\title{
Diagnosing Antibiotic Resistance Using Nucleic Acid Enzymes and Gold Nanoparticles
}

Mohamed A. Abdou Mohamed1,2,3,F, Hannah N. Kozlowski1,2,4,F, Jisung Kim ${ }^{1,2,4, \mp}$, Kyryl

Zagorovsky ${ }^{1,2}$, Melinda Kantor ${ }^{5}$, Jordan. J. Feld ${ }^{6}$, Samira Mubareka ${ }^{7,8}$, Tony Mazzulli5,8,

Warren. C. W. Chan ${ }^{1,2,4,9,10,11^{*}}$ 


\section{Supplementary Information Text}

\section{Materials and Methods}

RPA for multiplex screening and cross-reactivity test of antibiotic resistance genes. For cross-reactivity test of the first multiplexed RPA group, a premix solution containing $7 \mu \mathrm{L}$ of blaZ forward and reverse primer mix (5 pmol $/ \mu \mathrm{L}$ per primer), $8 \mu \mathrm{L}$ of $v a n A$ primer mix $(5 \mathrm{pmol} / \mu \mathrm{L}$ per primer $), 2.5 \mu \mathrm{L}$ of tetK primer mix $(5 \mathrm{pmol} / \mu \mathrm{L}$ per primer), $13 \mu \mathrm{L}$ of aph3iiia primer mix ( $5 \mathrm{pmol} / \mu \mathrm{L}$ per primer), $3.5 \mu \mathrm{L}$ of ermA primer mix $(5 \mathrm{pmol} / \mu \mathrm{L}$ per primer), $145 \mu \mathrm{L}$ of rehydration buffer, $53.5 \mu \mathrm{L}$ of nuclease-free water, and $12.5 \mu \mathrm{L}$ of magnesium acetate $(280 \mathrm{mM})$ was prepared to make a total volume of $245 \mu \mathrm{L}$ The premix solution was then mixed with a target mix containing $1 \mu \mathrm{L}$ of blaZ $\left(10^{5}\right.$ copes $\left./ \mu \mathrm{L}\right), 1 \mu \mathrm{L}$ of vanA $\left(10^{5}\right.$ copes $\left./ \mu \mathrm{L}\right), 1 \mu \mathrm{L}$ of tetK $\left(10^{5}\right.$ copes $\left./ \mu \mathrm{L}\right), 1 \mu \mathrm{L}$ of aph3iiia $\left(10^{5}\right.$ copes $\left./ \mu \mathrm{L}\right)$, and $1 \mu \mathrm{L}$ of ermA $\left(10^{5}\right.$ copes/ $\left.\mu \mathrm{L}\right)$ synthetic target DNA for "All" condition, or $1 \mu \mathrm{L}$ of one of the five genes plus 4 $\mu \mathrm{L}$ of nuclease-free water to make a final volume of $250 \mu \mathrm{L}$. "None" condition contained $5 \mu \mathrm{L}$ of nuclease-free water instead of target DNA. For screening clinical isolates, a similar premix solution was prepared using $8.5 \mu \mathrm{L}$ of sterile water and $50 \mu \mathrm{L}$ of DNA extracted from bacteria $\left(10^{5} \mathrm{CFU} / \mathrm{mL}\right)$. Non-template control (NTC) contained 50 $\mu \mathrm{L}$ of water instead of extracted DNA. This solution was then transferred to a tube containing 5 lyophilized enzyme pellets. The tubes were vortexed and incubated at $37^{\circ} \mathrm{C}$ for $30 \mathrm{~min}$.

For cross-reactivity test of the second multiplexed RPA group, a premix solution containing $4.8 \mu \mathrm{L}$ of $m e c A$ forward and reverse primer mix ( $5 \mathrm{pmol} / \mu \mathrm{L}$ per primer), $4.8 \mu \mathrm{L}$ of $v a n B$ primer mix $(5 \mathrm{pmol} / \mu \mathrm{L}$ per primer), $3.5 \mu \mathrm{L}$ of tet $M$ primer mix $(5 \mathrm{pmol} / \mu \mathrm{L}$ per primer $), 4 \mu \mathrm{L}$ of acc 6 primer mix $(5 \mathrm{pmol} / \mu \mathrm{L}$ per primer $), 3.6 \mu \mathrm{L}$ of erm $C$ primer mix $(5$ $\mathrm{pmol} / \mu \mathrm{L}$ per primer), $118 \mu \mathrm{L}$ of rehydration buffer, $45.5 \mu \mathrm{L}$ of nuclease-free water, and $10 \mu \mathrm{L}$ of magnesium acetate $(280 \mathrm{mM})$ was prepared to make a total volume of $194.2 \mu \mathrm{L}$ The premix solution was then mixed with a target mix containing $1 \mu \mathrm{L}$ of mec $A\left(10^{5}\right.$ copes $\left./ \mu \mathrm{L}\right), 1 \mu \mathrm{L}$ of $v a n B\left(10^{5}\right.$ copes $\left./ \mu \mathrm{L}\right), 1 \mu \mathrm{L}$ of tet $M\left(10^{5}\right.$ copes $\left./ \mu \mathrm{L}\right), 1 \mu \mathrm{L}$ of acc6 $\left(10^{5}\right.$ copes $\left./ \mu \mathrm{L}\right)$, and $1 \mu \mathrm{L}$ of $\operatorname{erm} C\left(10^{5}\right.$ copes $\left./ \mu \mathrm{L}\right)$ synthetic target DNA for "All" condition, or $1 \mu \mathrm{L}$ of one of the five genes plus $4 \mu \mathrm{L}$ of sterile water to make a final volume of $199.2 \mu \mathrm{L}$. "None" condition contained $5 \mu \mathrm{L}$ of nuclease-free water instead of target DNA. For screening clinical isolates, a similar premix solution was prepared using $50 \mu \mathrm{L}$ of DNA extracted from bacteria $\left(10^{5} \mathrm{CFU} / \mathrm{mL}\right)$ without nuclease-free water. NTC contained $50 \mu \mathrm{L}$ of water instead of extracted DNA. This solution was then transferred to a tube containing 4 lyophilized enzyme pellets. The tube was vortexed and incubated at $37^{\circ} \mathrm{C}$ for $30 \mathrm{~min}$. The EZ-10 spin column DNA gel extraction kit (Bio Basic Inc.) was used to purify the RPA reactions. Products were visualized using gel electrophoresis with a 3\% agarose gel (135 V, 30-45 minutes). The low molecular weight DNA ladder was from New England Biolabs.

Denaturation and blocking of multiplexed RPA products. For cross-reactivity test and screening clinical isolates of the first multiplexed RPA group, $12 \mu \mathrm{L}$ of purified RPA product, $1 \mu \mathrm{L}$ of 5 blocking strands mix $(20 \mathrm{pmol} / \mu \mathrm{L}$ of each strand mix), and $2.5 \mu \mathrm{L}$ of $\mathrm{NaOH}(0.1 \mathrm{M})$ were mixed. The solution was incubated at room temperature for 5 $\min$. $2.5 \mu \mathrm{L}$ of HCL $(0.1 \mathrm{M})$ was added to the solution for neutralization.

For cross-reactivity test and screening clinical isolates of the second multiplexed RPA group, $6 \mu \mathrm{L}$ of purified RPA product, $6 \mu \mathrm{L}$ of 5 blocking strands mix $(24 \mathrm{pmol} / \mu \mathrm{L}$ each strand mix), and $3 \mu \mathrm{L}$ of $\mathrm{NaOH}(0.1 \mathrm{M})$ were mixed. The same incubation and neutralization process was used.

Polymerase chain reaction. PCR reactions were set up separately for each antibiotic resistance gene by mixing $12.5 \mu \mathrm{L}$ of $2 \mathrm{X}$ PCR master Mix (Thermo Fisher), $0.5 \mu \mathrm{L}$ of $10 \mu \mathrm{M}$ primer mix, $11 \mu \mathrm{L}$ nuclease free water, and $1 \mu \mathrm{L}$ of template DNA product extracted from bacterial clinical isolates. $1 \mu \mathrm{L}$ of $10^{5}$ copies $/ \mu \mathrm{L}$ of synthetic DNA was used as a positive control, and $1 \mu \mathrm{L}$ of nuclease free water as negative control. PCR included 40 seconds $95{ }^{\circ} \mathrm{C}$ initial denaturation step, and was carried out for 40 cycles with each cycle includes 30 seconds $95^{\circ} \mathrm{C}$ denaturation, 30 seconds primer melting step $\left(51^{\circ} \mathrm{C}\right.$ for erm $C ; 54^{\circ} \mathrm{C}$ for $m e c A$, blaZ, tet $K$, tet $M$, acc $6 ; 58^{\circ} \mathrm{C}$ for vanA, vanB, Aph3iiia, erm A), and 30 seconds $72^{\circ} \mathrm{C}$ polymerase extension. The reaction was terminated by 4 minutes $72^{\circ} \mathrm{C}$ extension, and cooling of the product to $4^{\circ} \mathrm{C} .3 \mu \mathrm{L}$ of the product were visualized on $3 \%$ agarose gel.

Assay design for carbapenem-resistant Enterobacteriaceae. We selected 4 different antibiotic resistance biomarker genes that confer resistance to 3 different classes of carbapenemases in enterobacteriaceae: KPC gene for class A (active-site serine $\beta$ lactamases), $O X A$ gene for class D (oxacillinases) and $V I M$ and $N D M$ genes for class B 
(metallo- $\beta$ lactamases). While there are other genes that could potentially cause carbapenem resistance, these genes include the most common carbapenemases globally ${ }^{1}$. To detect the chosen antibiotic resistance biomarkers with high specificity and minimal cross reactivity, we selected the most conserved regions of their genetic sequences using Basic Local Alignment Search Tool (BLAST) and designed the primers to amplify these regions. The amplified regions were then detected with sequence-specific probes using our MNAzyme-GNP readout platform. 

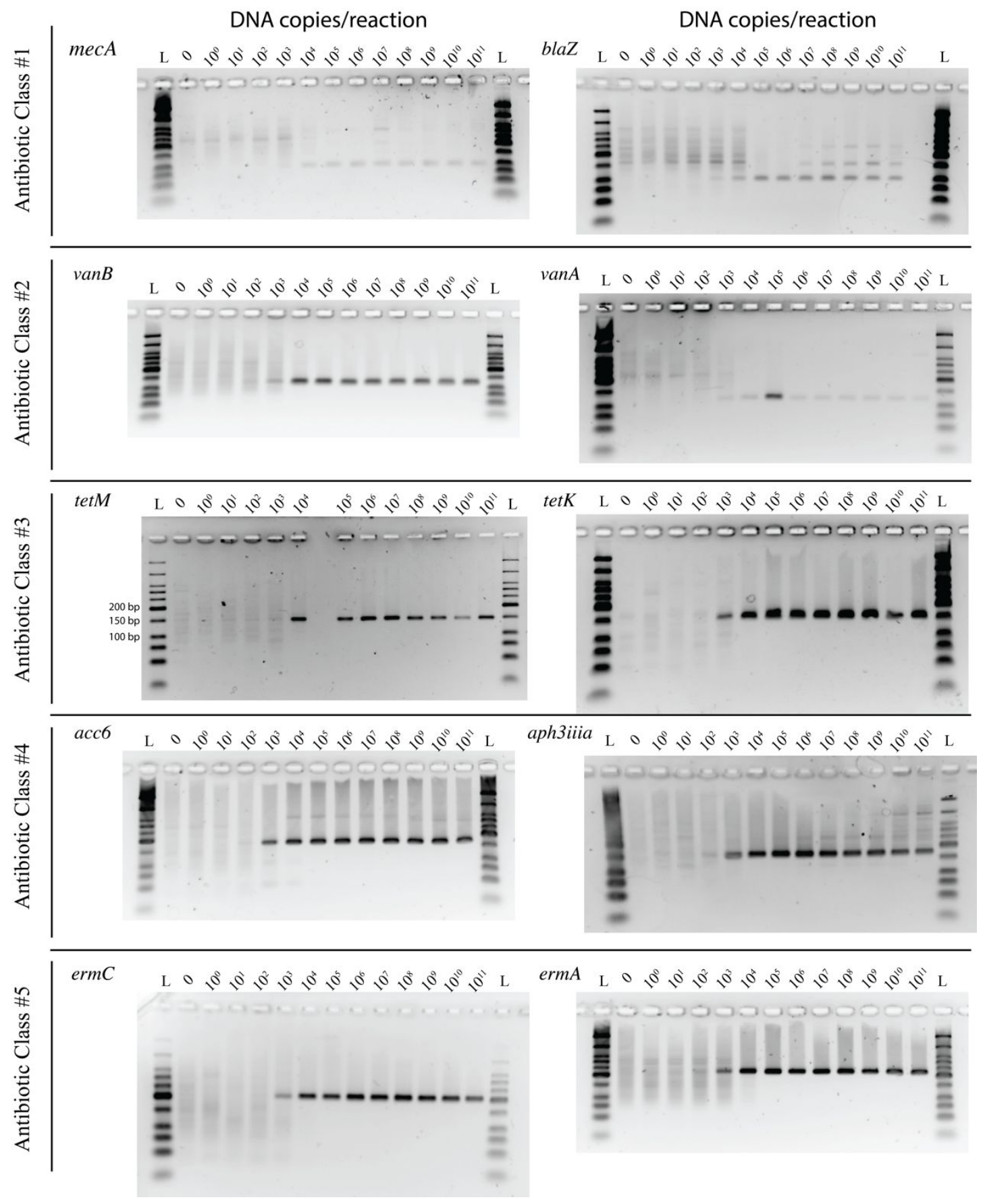

Fig. S1. Qualitative assessment of amplified antibiotic resistance genes using gel electrophoresis. Serially diluted antibiotic resistance genes were amplified via RPA and visualized on agarose gel. Clear bands that correspond to each gene can be observed when $10^{2}-10^{3}$ DNA copies were used in the RPA reaction. This is in correlation with our MNAzyme-GNP platform results. (L: low molecular weight DNA ladder). 
DNA copies/reaction

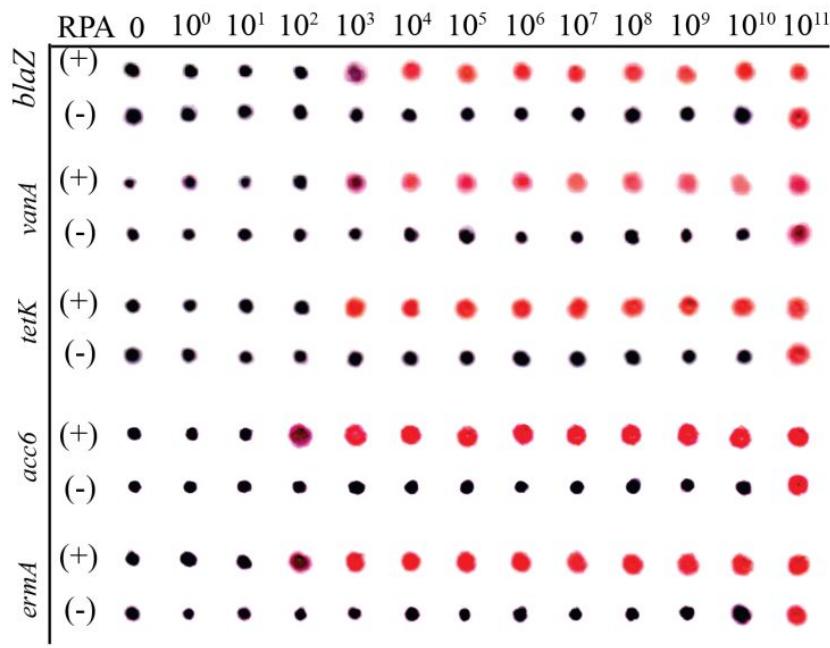

DNA copies/reaction

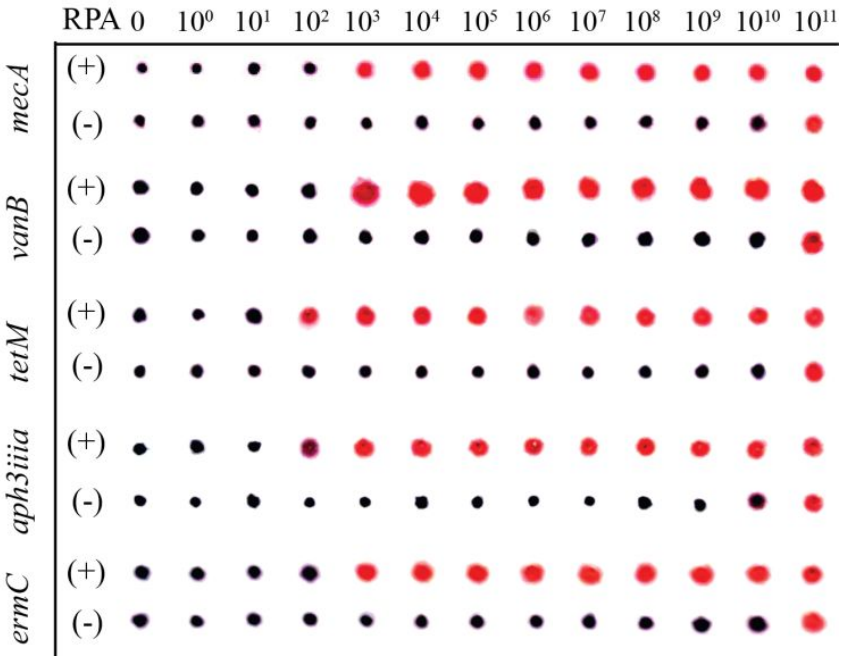

Fig. S2. Analytical sensitivity for identifying synthetic antibiotic resistance genes with and without RPA. 10 synthetic antibiotic resistance genes were serially diluted, amplified via RPA and identified using the MNAzymeGNP platform. The results were compared to no RPA conditions. Spot images capture TLC plate results. ImageJ was used to correct for lightness and contrast. 
$\triangle \nabla$ Without RPA
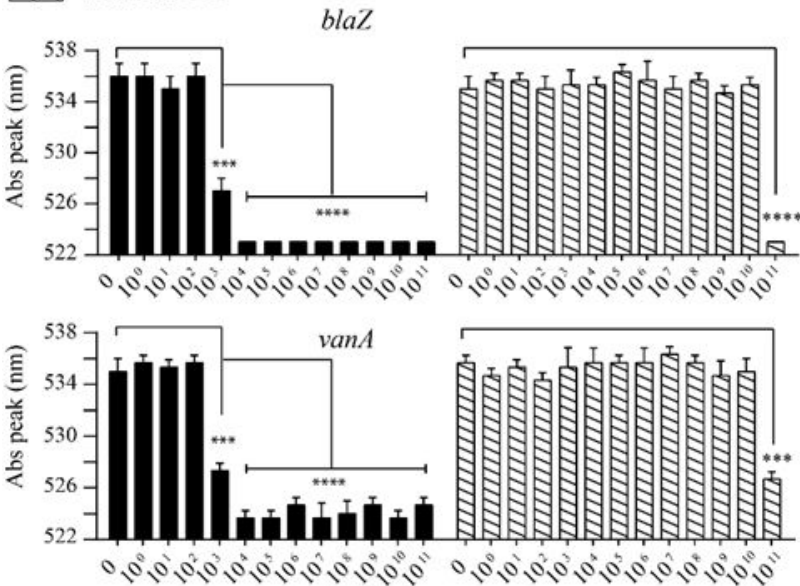

$0,000,000,0000,000,000$
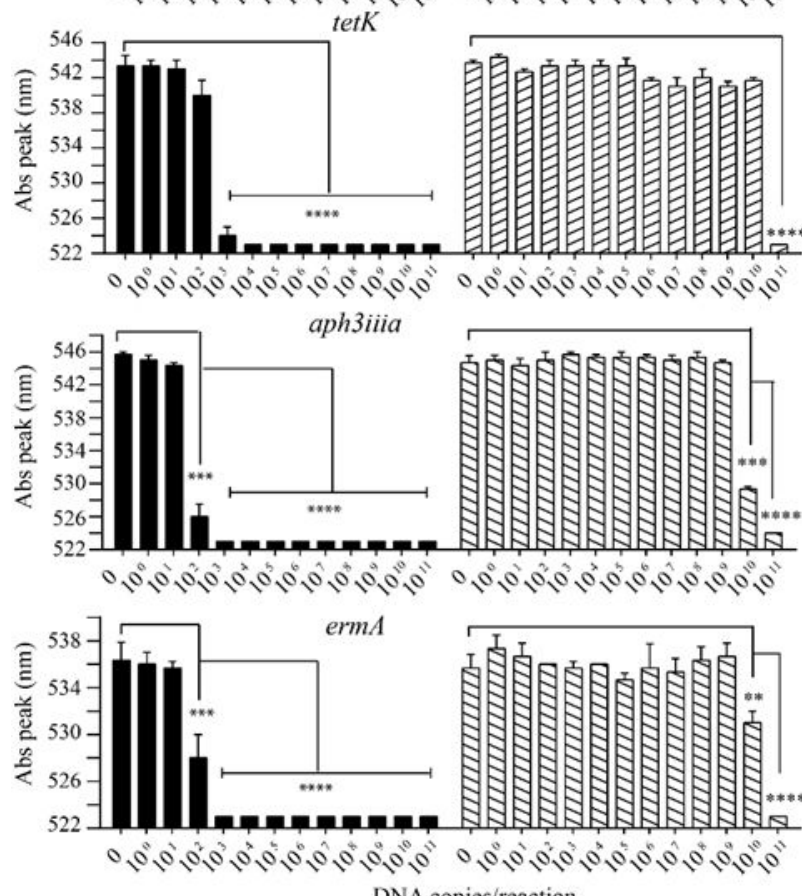
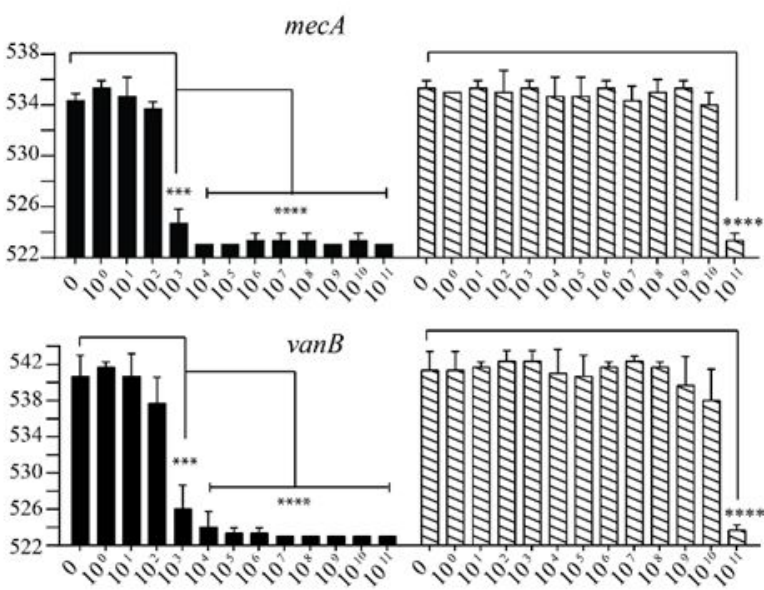

tetM

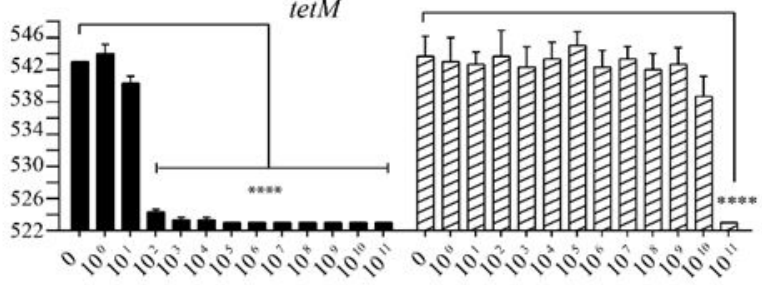

acc6
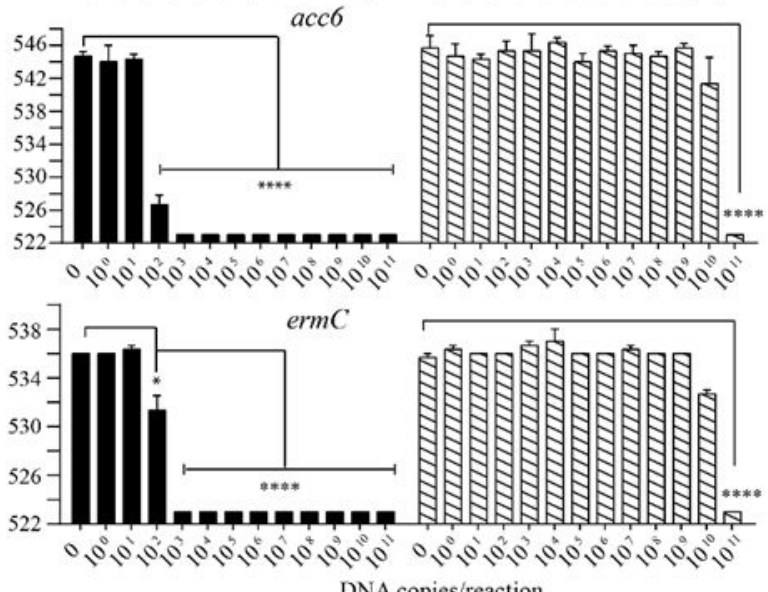

Fig. S3. Quantitative measurement of analytical sensitivity of antibiotic resistance genes with and without RPA. Wavelength peak absorbance measurement reveals the analytical sensitivity of MNAzyme-GNPs platform at $10^{2}$ $10^{3}$ DNA copies/reaction when RPA is used compared to $10^{11}$ DNA copies/reaction without RPA. Error bars denotes the standard deviation where $\mathrm{n}=3$. All statistics were calculated on excel using a two-tailed unpaired T-test assuming two-sample equal variance $\left({ }^{*} \mathrm{p} \leq 0.05,{ }^{* *} \mathrm{p}<0.001,{ }^{* * *} \mathrm{p}<0.0001\right.$ and $\left.* * * * \mathrm{p}<0.00001\right)$ 




Fig. S4. Screening clinical isolates for identification of antibiotic resistance genes using singleplex RPA and MNAzyme-GNPs platform. Three Staphylococcus aureus strains (MSSA, MRSA-41, and MRSA-44) were screened to test for presence of the 10 antibiotic resistance genes. "EBS" control is composed of elution buffer of DNA purification kit and blocking strands to test aggregation of GNPs. Spot images capture TLC plate results. ImageJ was used to correct for lightness and contrast. Red spots indicate the presence of genes while dark purple/blue spots indicate the absence of gene. (NTC: non-template control) 



Fig. S5. Detection of antibiotic resistance genes in bacterial strains using PCR. The gel electrophoresis images show the presence of antibiotic resistance genes in MRSA-44 (lane 2), MRSA-41 (lane 3) and MSSA (lane 4) strains. Synthetic antibiotic resistance genes (lane 5) was used as the positive control while NTC (lane 1) was used as the negative control. (L: low molecular weight DNA ladder). 

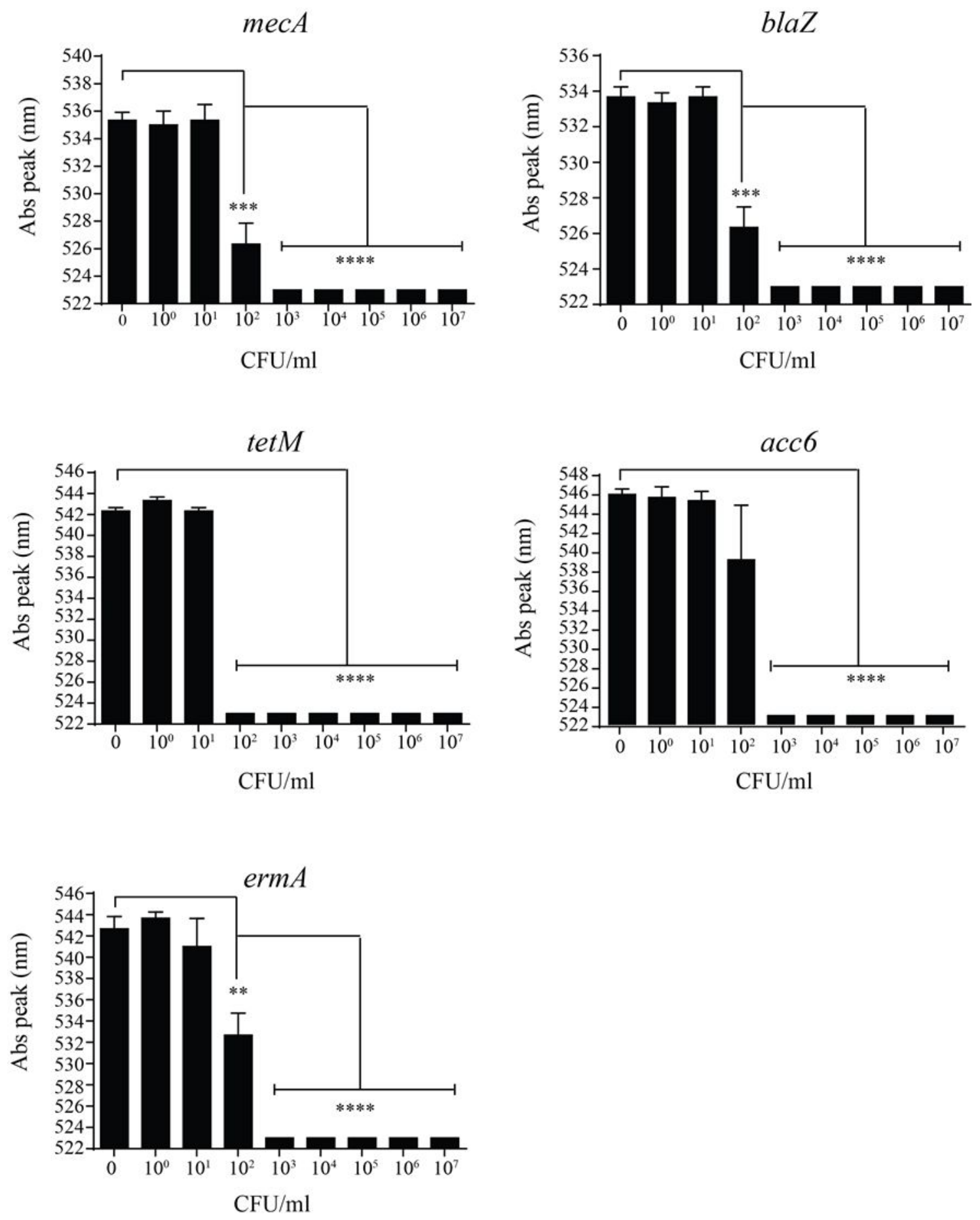

Fig. S6. Quantitative measurement of analytical sensitivity of antibiotic resistance genes from MRSA-44. Five antibiotic resistance genes are shown: mecA, blaZ, tetM, acc6 and ermA. Wavelength peak absorbance measurement reveals the analytical sensitivity of MNAzyme-GNPs platform at $10^{2}-10^{3} \mathrm{CFU} / \mathrm{ml}$. Error bars denotes the standard deviation where $\mathrm{n}=3$. All statistics were calculated on excel using a two-tailed unpaired T-test assuming two-sample equal variance $\left({ }^{*} \mathrm{p} \leq 0.05, * * \mathrm{p}<0.001, * * * \mathrm{p}<0.0001\right.$ and $\left.* * * * \mathrm{p}<0.0001\right)$ 
A) Oxacillin ( $m e c A$ ) and Penicillin ( $m e c A$ and blaZ)

\section{mecA}

\begin{tabular}{ccccccccccc}
\multicolumn{10}{c}{ Oxacillin Sensitive Isolates $(\mathrm{n}=20)$} \\
\hline 1 & 2 & 3 & 4 & 5 & 6 & 7 & 8 & 9 & 10 \\
$\bullet$ & $\bullet$ & $\bullet$ & $\bullet$ & $\bullet$ & $\bullet$ & $\bullet$ & $\bullet$ & $\bullet$ & $\bullet$ \\
11 & 12 & ${ }_{13}$ & ${ }_{14}$ & ${ }_{15}$ & ${ }_{16}$ & 17 & ${ }_{18}$ & 19 & ${ }_{20}$ \\
$\bullet$ & $\bullet$ & $\bullet$ & $\bullet$ & $\bullet$ & $\bullet$ & $\bullet$ & $\bullet$ & $\bullet$ & $\bullet$
\end{tabular}

\begin{tabular}{|c|c|c|c|c|c|c|c|c|c|}
\hline \multicolumn{10}{|c|}{ Oxacillin Resistant Isolates $(n=80)$} \\
\hline 21 & 22 & 23 & 24 & 25 & 26 & 27 & 28 & 29 & 30 \\
\hline $\mathbf{\theta}$ & (8) & C & 8 & $\theta$ & Q & $\mathbb{E}$ & $\theta$ & $\mathrm{e}$ & $\boldsymbol{\theta}$ \\
\hline 31 & 32 & 33 & 34 & 35 & 36 & 37 & 38 & 39 & 40 \\
\hline e & e & e & e & e & e & e & e & - & - \\
\hline 41 & 42 & 43 & 44 & 45 & 46 & 47 & 48 & 49 & so \\
\hline • & C) & e & - & 0 & • & C & C & e & - \\
\hline 51 & 52 & 53 & 54 & s5 & 56 & 57 & 58 & 59 & 60 \\
\hline - & - & e & - & - & - & ; & $\bullet$ & e & e \\
\hline 61 & 62 & 63 & 64 & 65 & 66 & 67 & 68 & 69 & 70 \\
\hline e & - & 0 & e & e & e & e & e & e & * \\
\hline 71 & 72 & 73 & 74 & 75 & 76 & $n$ & 78 & 79 & 80 \\
\hline$\theta$ & $\theta$ & 6 & ○ & • & $\mathbf{b}$ & $\theta$ & $\bullet$ & $\theta$ & $\bullet$ \\
\hline 81 & 82 & 83 & 84 & 85 & 86 & 87 & 88 & 89 & 90 \\
\hline • & ? & e & - & e & e & • & • & e & 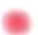 \\
\hline 91 & 92 & 93 & 94 & 95 & 96 & 97 & 98 & 99 & 100 \\
\hline 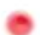 & $\theta$ & • & e & 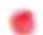 & $\theta$ & $\rho$ & $\bullet$ & $\bullet$ & $\theta$ \\
\hline
\end{tabular}

Negative Controls

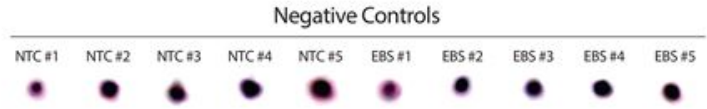

\section{blaz}

\begin{tabular}{|c|c|c|c|c|c|c|c|c|c|}
\hline \multicolumn{10}{|c|}{ Penicillin Sensitive Isolates $(n=0)$} \\
\hline & & & & & & & & & \\
\hline \multicolumn{10}{|c|}{ Penicillin Resistant Isolates $(n=100)$} \\
\hline 1 & 2 & 3 & 4 & 5 & 6 & 7 & 8 & 9 & 10 \\
\hline e & e & 0 & C & $\mathbf{P}$ & e & $\bullet$ & $\boldsymbol{\theta}$ & e & $\bullet$ \\
\hline 11 & 12 & 13 & 14 & 15 & 16 & 17 & 18 & 19 & 20 \\
\hline$\bullet$ & $\mathbf{\theta}$ & $\bullet$ & e & P & 8 & $\bullet$ & B & a & e \\
\hline 21 & 22 & 23 & 24 & 25 & 26 & 27 & 28 & 29 & 30 \\
\hline 6 & $\mathbf{\theta}$ & P & $\bullet$ & e & $\boldsymbol{e}$ & $\mathbf{e}$ & e & o & $\theta$ \\
\hline 31 & 32 & 33 & 34 & 35 & 36 & 37 & 38 & 39 & 40 \\
\hline$\bullet$ & $e$ & $\bullet$ & $\bullet$ & $\theta$ & 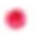 & $\theta$ & $\theta$ & e & $\bullet$ \\
\hline 41 & 42 & 43 & 44 & 45 & 46 & 47 & 48 & 49 & so \\
\hline C & e & 0 & $\theta$ & $\bullet$ & $\mathbf{a}$ & $\theta$ & $\mathbf{c}$ & $\bullet$ & C \\
\hline 51 & 52 & 53 & 54 & 55 & 56 & 57 & 58 & 59 & 60 \\
\hline$\bullet$ & e & $\theta$ & $\bullet$ & 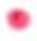 & • & e & O & $\bullet$ & $\bullet$ \\
\hline 61 & 62 & 63 & 64 & 65 & 66 & 67 & 68 & 69 & 70 \\
\hline$\bullet$ & $\theta$ & $\bullet$ & ( & $\boldsymbol{c}$ & e & 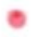 & $\theta$ & 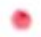 & e \\
\hline 71 & 72 & 73 & 74 & 75 & 76 & 77 & 78 & 79 & 80 \\
\hline 6 & $\bullet$ & $\theta$ & $\bullet$ & $\bullet$ & e & $\bullet$ & • & $\bullet$ & $\bullet$ \\
\hline 81 & 82 & 83 & 84 & 85 & 86 & 87 & 88 & 89 & 90 \\
\hline 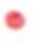 & $\bullet$ & $\bullet$ & $\theta$ & • & 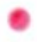 & $\bullet$ & e & $\bullet$ & 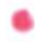 \\
\hline 91 & 92 & 93 & 94 & 95 & 96 & 97 & 98 & 99 & 100 \\
\hline e & $\bullet$ & $\theta$ & $\mathbf{e}$ & • & e & e & $\theta$ & $\bullet$ & $\bullet$ \\
\hline
\end{tabular}

Negative Controls

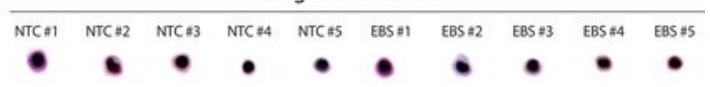


B) Vancomycin (vanA and vanB)

\section{vanA}

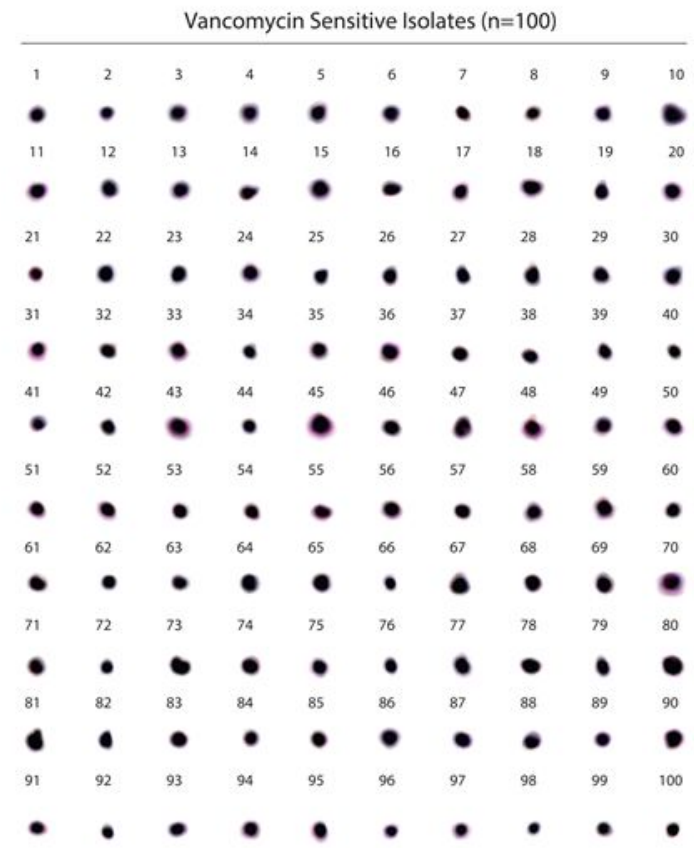

Vancomycin Resistant Isolates $(\mathrm{n}=0)$

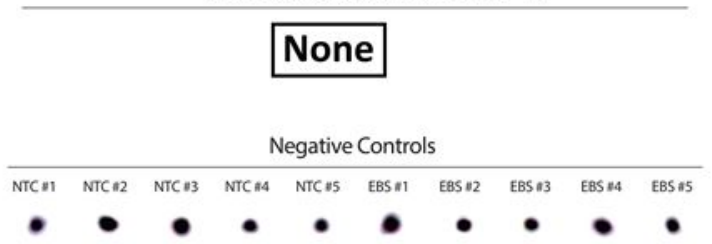

vanB

\begin{tabular}{|c|c|c|c|c|c|c|c|c|c|}
\hline \multicolumn{10}{|c|}{ Vancomycin Sensitive Isolates $(n=100)$} \\
\hline 1 & 2 & 3 & 4 & 5 & 6 & 7 & 8 & 9 & 10 \\
\hline$\bullet$ & $\bullet$ & $\bullet$ & $\bullet$ & $\bullet$ & $\bullet$ & $\bullet$ & $\bullet$ & $\bullet$ & $\bullet$ \\
\hline 11 & 12 & 13 & 14 & 15 & 16 & 17 & 18 & 19 & 20 \\
\hline$\bullet$ & $\bullet$ & $\bullet$ & $\bullet$ & $\bullet$ & $\bullet$ & $\bullet$ & $\bullet$ & $\bullet$ & $\bullet$ \\
\hline 21 & 22 & 23 & 24 & 25 & 26 & 27 & 28 & 29 & 30 \\
\hline$\bullet$ & $\bullet$ & $\bullet$ & $\bullet$ & $\bullet$ & $\bullet$ & $\bullet$ & $\bullet$ & $\bullet$ & $\bullet$ \\
\hline 31 & 32 & 33 & 34 & 35 & 36 & 37 & 38 & 39 & 40 \\
\hline$\bullet$ & $\bullet$ & $\bullet$ & $\bullet$ & $\bullet$ & $\bullet$ & $\bullet$ & $\bullet$ & $\bullet$ & $\bullet$ \\
\hline 41 & 42 & 43 & 44 & 45 & 46 & 47 & 48 & 49 & 50 \\
\hline$\bullet$ & $\bullet$ & $\bullet$ & $\bullet$ & $\bullet$ & • & $\bullet$ & $\bullet$ & $\bullet$ & $\bullet$ \\
\hline 51 & 52 & 53 & $\$ 4$ & 55 & 56 & 57 & 58 & 59 & 60 \\
\hline • & $\bullet$ & e & - & $\bullet$ & $\bullet$ & $\bullet$ & $\bullet$ & $\bullet$ & • \\
\hline 61 & 62 & 63 & 64 & 65 & 66 & 67 & 68 & 69 & 70 \\
\hline$\bullet$ & 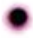 & $\bullet$ & $\bullet$ & 0 & $\bullet$ & $\bullet$ & $\bullet$ & e & $\bullet$ \\
\hline 71 & 72 & 73 & 74 & 75 & 76 & 77 & 78 & 79 & 80 \\
\hline$\bullet$ & $\bullet$ & $\bullet$ & $\bullet$ & $\bullet$ & $\bullet$ & $\bullet$ & $\bullet$ & $\bullet$ & 0 \\
\hline 81 & 82 & 83 & 84 & 85 & 86 & 87 & 88 & 89 & 90 \\
\hline 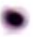 & $\bullet$ & 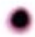 & $\bullet$ & ○ & $\bullet$ & $\bullet$ & $\bullet$ & • & $\bullet$ \\
\hline 91 & 92 & 93 & 94 & 95 & 96 & 97 & 98 & 99 & 100 \\
\hline$\bullet$ & $\bullet$ & $\bullet$ & $\bullet$ & $\bullet$ & • & $\bullet$ & $\bullet$ & $\bullet$ & $\bullet$ \\
\hline
\end{tabular}

Vancomycin Resistant Isolates $(\mathrm{n}=0$ )

\section{None}

Negative Controls




C) Doxycycline (tetK and tetM)

\section{tetK}

Doxycycline Sensitive Isolates $(n=90)$

\begin{tabular}{|c|c|c|c|c|c|c|c|c|c|}
\hline \multicolumn{10}{|c|}{ Doxycycline Sensitive Isolates $(n=90)$} \\
\hline 1 & 2 & 4 & 5 & 6 & 7 & 8 & 9 & 10 & 11 \\
\hline$\bullet$ & $\bullet$ & $\bullet$ & $\bullet$ & $\bullet$ & $\bullet$ & $\bullet$ & $\bullet$ & $\bullet$ & $\bullet$ \\
\hline 12 & 13 & 14 & 16 & 17 & 18 & 19 & 20 & 21 & 22 \\
\hline$\bullet$ & $\bullet$ & $\bullet$ & $\bullet$ & $\bullet$ & $\bullet$ & $\bullet$ & $\bullet$ & $\bullet$ & $\bullet$ \\
\hline 23 & 24 & 25 & 26 & 27 & 28 & 29 & 30 & 31 & 32 \\
\hline$\bullet$ & $\bullet$ & $\bullet$ & $\bullet$ & $\bullet$ & $\bullet$ & $\bullet$ & $\bullet$ & $\bullet$ & $\bullet$ \\
\hline 33 & 34 & 35 & 36 & 37 & 38 & 39 & 40 & 42 & 43 \\
\hline$\bullet$ & $\bullet$ & $\bullet$ & $\bullet$ & $\bullet$ & $\bullet$ & • & • & $\bullet$ & $\bullet$ \\
\hline 44 & 45 & 46 & 47 & 48 & 50 & 51 & 52 & 53 & 54 \\
\hline$\bullet$ & $\bullet$ & $\bullet$ & $\bullet$ & 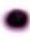 & $\bullet$ & $\bullet$ & $\bullet$ & • & $\bullet$ \\
\hline ss & 56 & 57 & 59 & 60 & 61 & 62 & 63 & 64 & 65 \\
\hline$\bullet$ & $\bullet$ & $\bullet$ & $\bullet$ & • & $\bullet$ & $\bullet$ & $\bullet$ & $\boldsymbol{\bullet}$ & 0 \\
\hline 66 & 67 & 68 & 69 & 72 & 73 & 74 & 75 & 76 & 77 \\
\hline$\bullet$ & $\bullet$ & $\bullet$ & $\bullet$ & $\bullet$ & $\bullet$ & $\bullet$ & $\bullet$ & $\bullet$ & $\bullet$ \\
\hline 78 & 79 & 80 & 81 & 82 & 83 & 85 & 87 & 88 & 89 \\
\hline • & $\bullet$ & • & $\bullet$ & $\bullet$ & $\bullet$ & $\bullet$ & $\bullet$ & $\bullet$ & $\bullet$ \\
\hline 91 & 92 & 93 & 94 & 95 & 96 & 97 & 98 & 99 & 100 \\
\hline$\bullet$ & $\bullet$ & $\bullet$ & 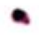 & $\bullet$ & $\bullet$ & $\bullet$ & $\bullet$ & $\bullet$ & $\bullet$ \\
\hline
\end{tabular}

Doxycycline Resistant Isolates $(n=10)$

\begin{tabular}{llllllllll}
\hline 3 & 15 & 41 & 49 & 58 & 70 & 71 & 84 & 86 & 90 \\
\hline & 0 & 0 & 0 & 0 & $\bullet$ & 0 & $\bullet$ & 9 & $\bullet$
\end{tabular}

Negative Controls

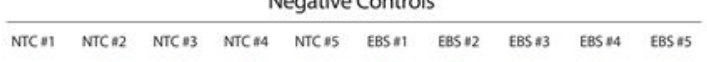

tetM

Doxycycline Sensitive Isolates $(n=90)$

\begin{tabular}{cccccccccc}
\hline 1 & 2 & 4 & 5 & 6 & 7 & 8 & 9 & 10 & 11 \\
$\bullet$ & $\bullet$ & $\bullet$ & $\bullet$ & $\bullet$ & $\bullet$ & $\bullet$ & $\bullet$ & $\bullet$ & $\bullet$ \\
12 & 13 & 14 & ${ }^{2} 6$ & 17 & 18 & 19 & 20 & 21 & 22 \\
$\bullet$ & $\bullet$ & $\bullet$ & $\bullet$ & $\bullet$ & $\bullet$ & $\bullet$ & $\bullet$ & $\bullet$ & $\bullet$ \\
23 & 24 & 25 & 26 & 27 & 28 & 29 & 30 & 31 & 32 \\
$\bullet$ & $\bullet$ & $\bullet$ & $\bullet$ & $\bullet$ & $\bullet$ & $\bullet$ & $\bullet$ & $\bullet$ & $\bullet$ \\
33 & 34 & 35 & 36 & 37 & 38 & 39 & 40 & 42 & 43 \\
$\bullet$ & $\bullet$ & $\bullet$ & $\bullet$ & $\bullet$ & $\bullet$ & $\bullet$ & $\bullet$ & $\bullet$ & $\bullet$ \\
44 & 45 & 46 & 47 & 48 & 50 & 51 & 52 & 53 & 54 \\
$\bullet$ & $\bullet$ & $\bullet$ & $\bullet$ & $\bullet$ & $\bullet$ & $\bullet$ & $\bullet$ & $\bullet$ & $\bullet$ \\
55 & 56 & 57 & 59 & 60 & 61 & 62 & 63 & 64 & 65 \\
$\bullet$ & $\bullet$ & $\bullet$ & $\bullet$ & $\bullet$ & $\bullet$ & $\bullet$ & $\bullet$ & $\bullet$ & $\bullet$ \\
66 & 67 & 68 & 69 & 72 & 73 & 74 & 75 & 76 & 77 \\
$\bullet$ & $\bullet$ & $\bullet$ & $\bullet$ & $\bullet$ & $\bullet$ & $\bullet$ & $\bullet$ & $\bullet$ & $\bullet$ \\
78 & 79 & 80 & 81 & 82 & 83 & 85 & 87 & 88 & 89 \\
$\bullet$ & $\bullet$ & $\bullet$ & $\bullet$ & $\bullet$ & $\bullet$ & $\bullet$ & $\bullet$ & $\bullet$ & $\bullet$ \\
91 & 92 & 93 & 94 & 95 & 96 & 97 & 98 & 99 & 100 \\
$\bullet$ & $\bullet$ & $\bullet$ & $\bullet$ & $\bullet$ & $\bullet$ & $\bullet$ & $\bullet$ & $\bullet$ & $\bullet$
\end{tabular}

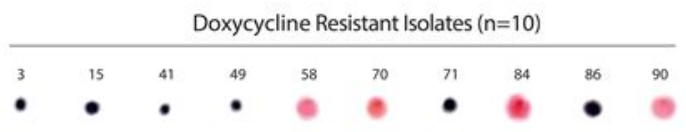

Negative Controls

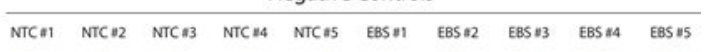


D) Erythromycin (ermA, ermC and msrA)
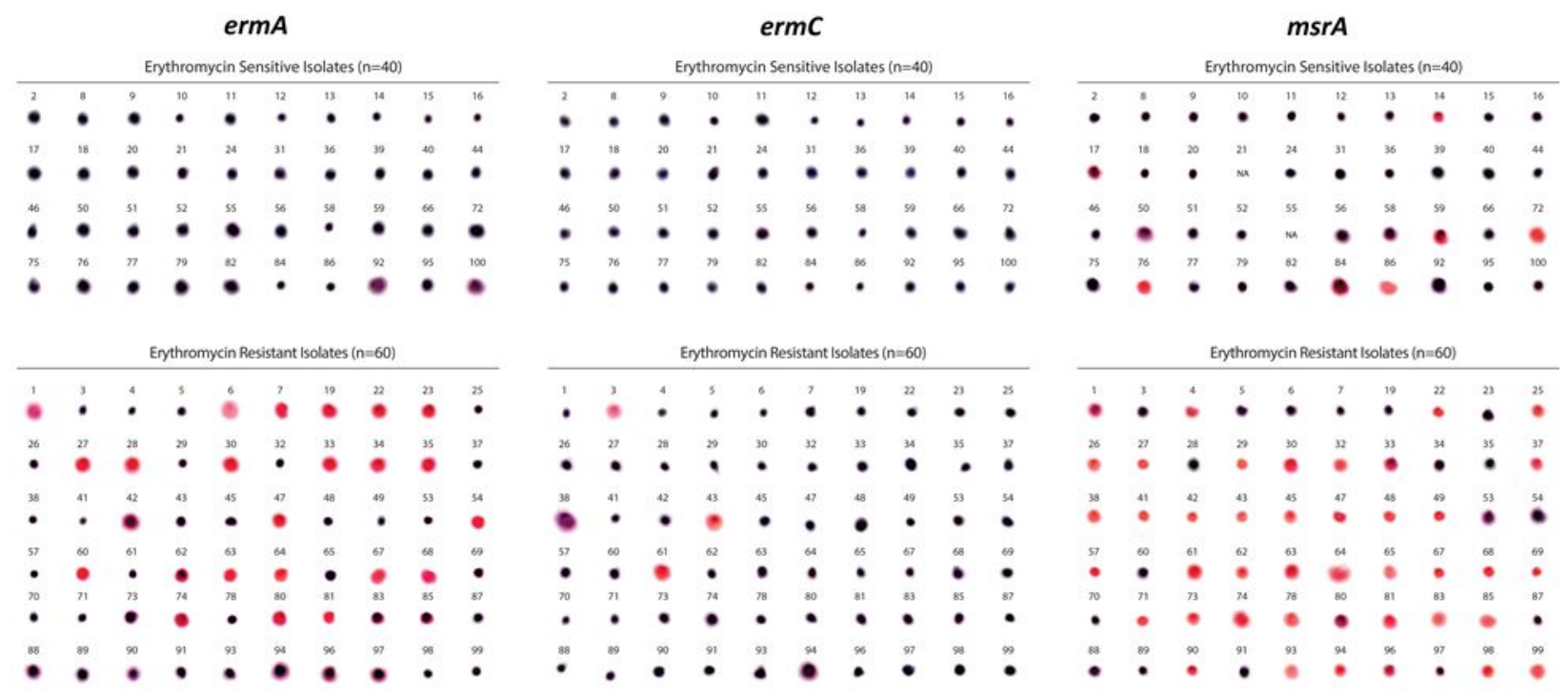

\section{Negative Controls}
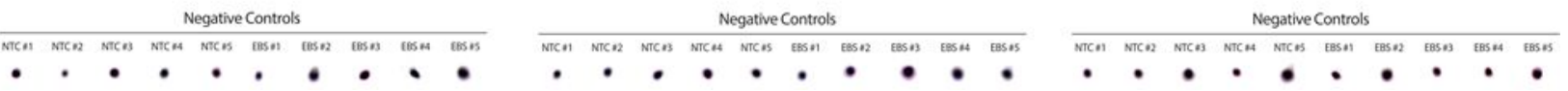

E) CRE panel

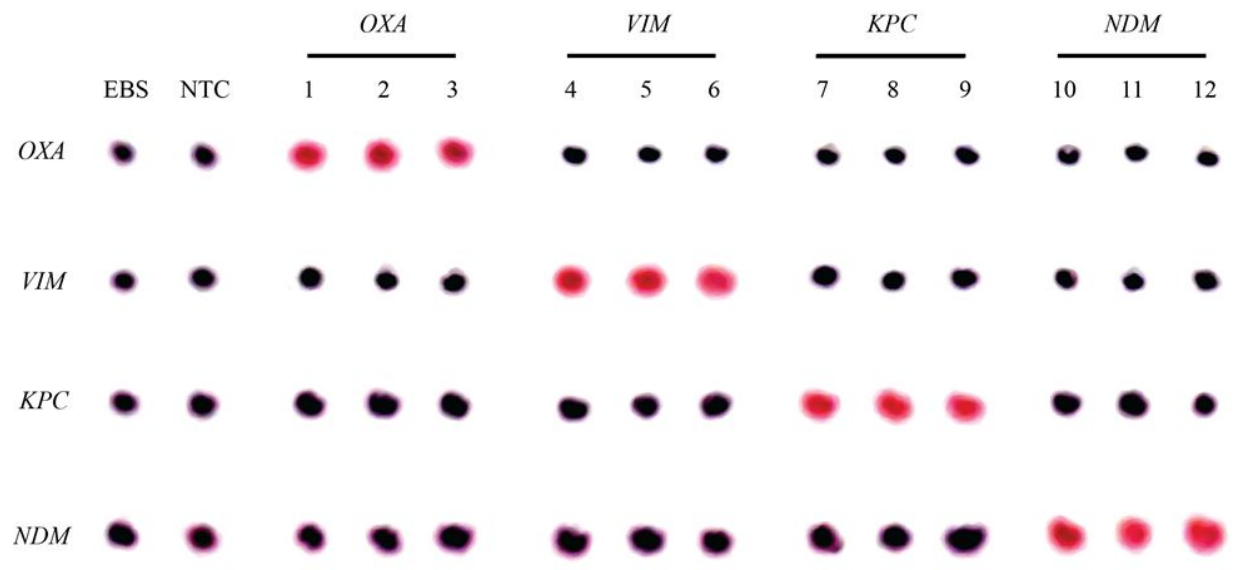

Fig S7. Profiling antibiotic resistance from clinical isolates. A) Penicillin and Oxacillin, B) Vancomycin, C) Doxycycline, D) Erythromycin and E) Carbapenem resistance. NA for sample\#21 and 55 for $m s r A$ gene identification denotes insufficient samples for testing. Spot images capture TLC plate results. ImageJ was used to correct for lightness and contrast. Red spots indicate the presence of genes while dark purple/blue spots indicate the absence of gene. 

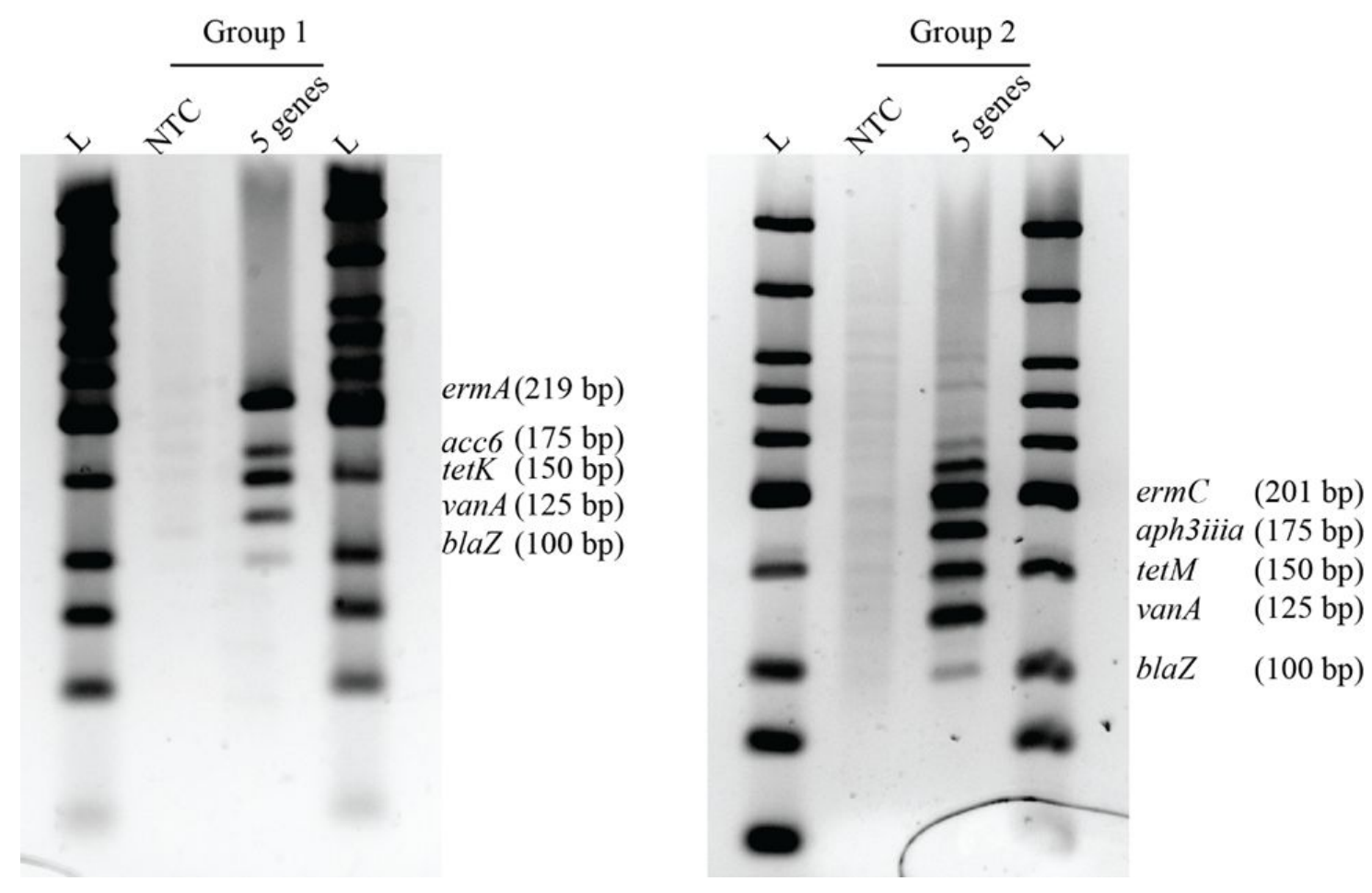

Fig. S8. Multiplex RPA reaction using 5 antibiotic resistance genes simultaneously. Gel electrophoresis images show the presence of the amplified products of RPA of the 5 antibiotic resistance genes with marked different band sizes. (L: low molecular weight DNA ladder) 
A)

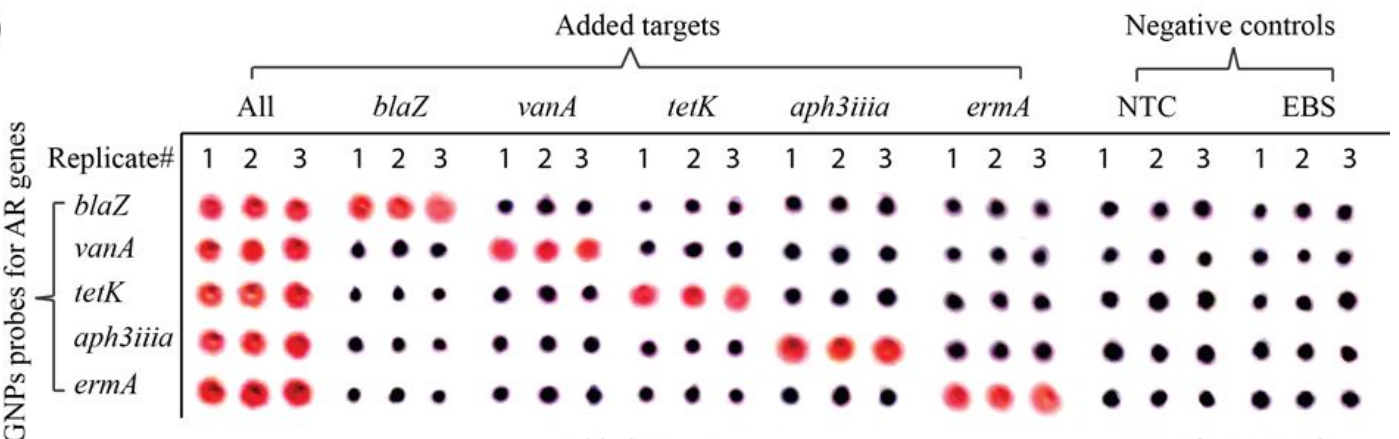

B)

Added targets

Negative controls

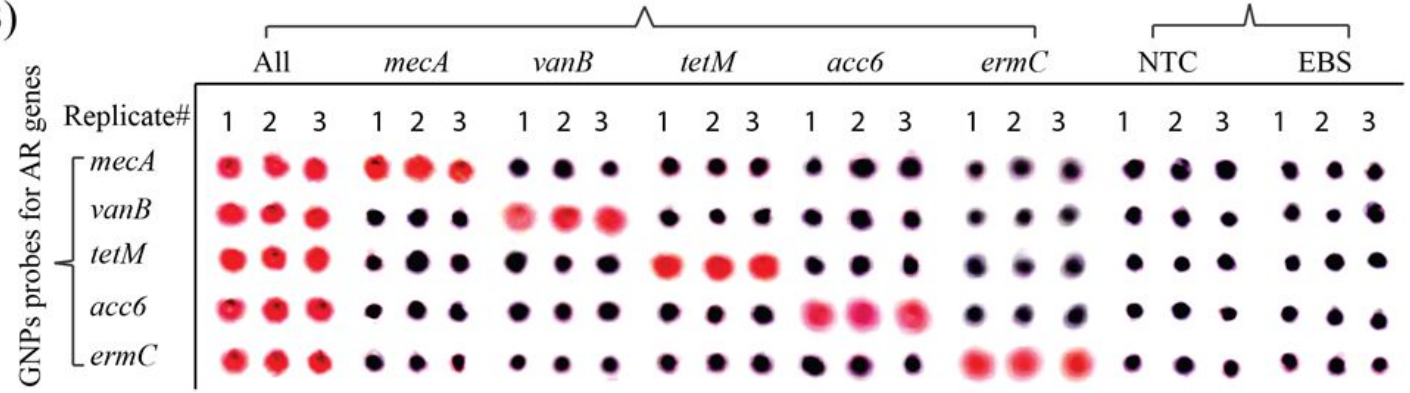

Fig. S9. Cross-reactivity test for two groups of antibiotic resistance genes. Synthetic antibiotic resistance gene(s) were added to the multiplexed RPA solution containing primers for (A) blaZ, vanA, tetK, aph3iiia, and ermA, or (B) $m e c A, \operatorname{van} B, \operatorname{tet} M, a c c 6$, and erm C. Amplicons were detected with MNAzyme-GNP platform. "None" indicates no template control of multiplexed RPA reaction. "All" indicates that all antibiotic resistance genes of the group are added to multiplexed RPA reaction. Spot images capture TLC plate results. ImageJ was used to correct for lightness and contrast. 
Table S1. List of DNA sequences for the first antibiotic resistance group.

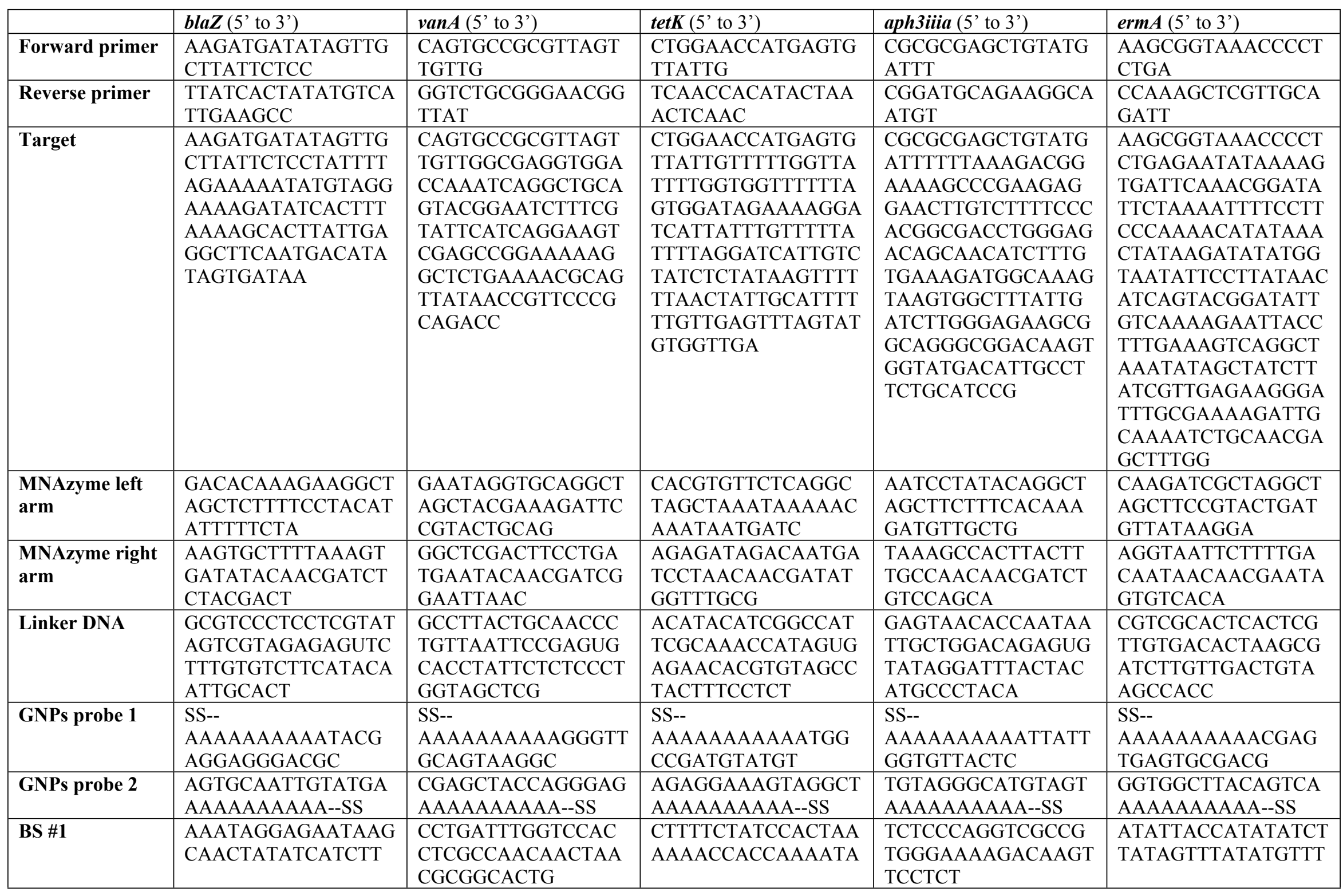




\begin{tabular}{|c|c|c|c|c|c|}
\hline & & & $\begin{array}{l}\text { ACCAAAAACAATAAC } \\
\text { ACTCATGGTTCCAG }\end{array}$ & & $\begin{array}{l}\text { TGGGAAGGAAAATTT } \\
\text { TAG }\end{array}$ \\
\hline BS \#2 & $\begin{array}{l}\text { TTATCACTATATGTCA } \\
\text { TTGAAGCCTCAAT }\end{array}$ & $\begin{array}{l}\text { GGTCTGCGGGAACGG } \\
\text { TTATAACTGCGTTTTC } \\
\text { AGAGCCTTTTTCC }\end{array}$ & $\begin{array}{l}\text { TCAACCACATACTAA } \\
\text { ACTCAACAAAAAATG } \\
\text { CAATAGTTAA } \\
\text { AAAACTTAT }\end{array}$ & $\begin{array}{l}\text { TCGGGCTTTTCCGTCT } \\
\text { TTAAAAAATCATACA } \\
\text { GCTCGCGCG }\end{array}$ & $\begin{array}{l}\text { AATATCCGTTTGAAT } \\
\text { CACTTTTATATTCTCA } \\
\text { GAGGGGTTTACCGCT } \\
\mathrm{T}\end{array}$ \\
\hline BS \#3 & $\mathrm{NA}$ & NA & NA & $\begin{array}{l}\text { CGGATGCAGAAGGCA } \\
\text { ATGTCATACCACTTG }\end{array}$ & $\begin{array}{l}\text { CCAAAGCTCGTTGCA } \\
\text { GATTTTGCAATCTTTT } \\
\text { CGCAAATCC }\end{array}$ \\
\hline BS \#4 & NA & NA & NA & $\begin{array}{l}\text { TCCGCCCTGCCGCTTC } \\
\text { TCCCAAGATCAA }\end{array}$ & $\begin{array}{l}\text { CTTCTCAACGATAAG } \\
\text { ATAGCTATATTTAGC } \\
\text { CTGACTTTCAA }\end{array}$ \\
\hline
\end{tabular}


Table S2. List of DNA sequences for the second antibiotic resistance group.

\begin{tabular}{|c|c|c|c|c|c|c|}
\hline & $\operatorname{mec} A$ (5' to 3') & $\operatorname{vanB}\left(5^{\prime}\right.$ to 3') & $\operatorname{tetM}\left(5^{\prime}\right.$ to $\left.3^{\prime}\right)$ & $\operatorname{acc6}\left(5^{\prime}\right.$ to 3') & $\operatorname{ermC}\left(5^{\prime}\right.$ to $\left.3^{\prime}\right)$ & $\operatorname{msr} A\left(5^{\prime}\right.$ to $\left.3^{\prime}\right)$ \\
\hline Target & $\begin{array}{l}\text { AAGATATGAAGT } \\
\text { GGTAAATGGTAA } \\
\text { TATCGACTTAAA } \\
\text { ACAAGCAATAGA } \\
\text { ATCATCAGATAA } \\
\text { CATTTTCTTTGCT } \\
\text { AGAGTAGCACTC } \\
\text { GAATTAGGCAGT } \\
\text { AAG }\end{array}$ & $\begin{array}{l}\text { CATGATGTGTCG } \\
\text { GTAAAATCCGCA } \\
\text { ATAGAAATTGCT } \\
\text { GCGAACATTAAT } \\
\text { ACTGAAAAATTC } \\
\text { GATCCGCACTAC } \\
\text { ATCGGAATTACA } \\
\text { AAAAACGGCGTA } \\
\text { TGGAAGCTATGC } \\
\text { AAGAAGCCATGT } \\
\text { ACGGA }\end{array}$ & $\begin{array}{l}\text { GTGGAGCGATTA } \\
\text { CAGAATTAGGAA } \\
\text { GCGTGGACAAAG } \\
\text { GTACAACGAGGA } \\
\text { CGGATAATACGC } \\
\text { TTTTAGAACGTCA } \\
\text { GAGAGGAATTAC } \\
\text { AATTCAGACAGG } \\
\text { AATAACCTCTTTT } \\
\text { CAGTGGGAAAAT } \\
\text { ACGAAGGTGAAC } \\
\text { ATCATAGACACG } \\
\text { CCAG }\end{array}$ & $\begin{array}{l}\text { AGATTTGCCAGA } \\
\text { ACATGAATTACA } \\
\text { CGAGGGCAAAAA } \\
\text { AGAAGATTGTTA } \\
\text { TTTAATGGAATAT } \\
\text { AGATATGATGAT } \\
\text { AATGCCACAAAT } \\
\text { GTTAAGGCAATG } \\
\text { AAATATTTAATTG } \\
\text { AGCATTACTTTGA } \\
\text { TAATTTCAAAGT } \\
\text { AGATAGTATTGA } \\
\text { AATAATCGGTAG } \\
\text { TGGTTATGATAGT } \\
\text { GTG }\end{array}$ & $\begin{array}{l}\text { AGTACAGAGGTG } \\
\text { TAATTTCGTAACT } \\
\text { GCCATTGAAATA } \\
\text { GACCATAAATTA } \\
\text { TGCAAAACTACA } \\
\text { GAAAATAAACTT } \\
\text { GTTGATCACGAT } \\
\text { AATTTCCAAGTTT } \\
\text { TAAACAAGGATA } \\
\text { TATTGCAGTTTAA } \\
\text { ATTTCCTAAAAA } \\
\text { CCAATCCTATAA } \\
\text { AATATATGGTAA } \\
\text { TATACCTTATAAC } \\
\text { ATAAGTACGGAT } \\
\text { ATAATACGCAAA } \\
\text { ATTGT }\end{array}$ & $\begin{array}{l}\text { GAGGGAATTGAT } \\
\text { TGTTCTCCTAAAG } \\
\text { TGCAAATGGCAT } \\
\text { ACTATCGTCAACT } \\
\text { TGCTTATGAAGA } \\
\text { CATGCGTGACGT } \\
\text { TTCATTATTGCAA } \\
\text { TATTTAATGGATG } \\
\text { AAACGGATTCAT } \\
\text { CAGAATCATTCA } \\
\text { G }\end{array}$ \\
\hline $\begin{array}{l}\text { MNAzyme left } \\
\text { arm }\end{array}$ & $\begin{array}{l}\text { GACACAAAGAAG } \\
\text { GCTAGCTGATTCT } \\
\text { ATTGCTTGTTTTA } \\
\text { AG }\end{array}$ & $\begin{array}{l}\text { GAATAGGTGCAG } \\
\text { GCTAGCTGAATTT } \\
\text { TTCAGTATTAATG } \\
\text { TT }\end{array}$ & $\begin{array}{l}\text { CACGTGTTCTCAG } \\
\text { GCTAGCTTCTGAC } \\
\text { GTTCTAAAAGCG } \\
\text { TAT }\end{array}$ & $\begin{array}{l}\text { AATCCTATACAG } \\
\text { GCTAGCTAACAT } \\
\text { TTGTGGCATTATC } \\
\text { ATC }\end{array}$ & $\begin{array}{l}\text { CAAGATCGCTAG } \\
\text { GCTAGCTCAACA } \\
\text { AGTTTATTTTCTG } \\
\text { TAG }\end{array}$ & $\begin{array}{l}\text { CAAGATCGCTAG } \\
\text { GCTAGCTTCTTCA } \\
\text { TAAGCAAGTTGA } \\
\text { CGA }\end{array}$ \\
\hline $\begin{array}{l}\text { MNAzyme right } \\
\text { arm }\end{array}$ & $\begin{array}{l}\text { CAAAGAAAATGT } \\
\text { TATCTGATACAA } \\
\text { CGATCTCTACGA } \\
\text { CT }\end{array}$ & $\begin{array}{l}\text { ATTCCGATGTAGT } \\
\text { GCGGATCACAAC } \\
\text { GATCGGAATTAA } \\
\text { C }\end{array}$ & $\begin{array}{l}\text { TGTCTGAATTGTA } \\
\text { ATTCCTCACAAC } \\
\text { GATATGGTTTGC } \\
\text { G }\end{array}$ & $\begin{array}{l}\text { ATTAAATATTTCA } \\
\text { TTGCCTTACAACG } \\
\text { ATCTGTCCAGCA }\end{array}$ & $\begin{array}{l}\text { AACTTGGAAATT } \\
\text { ATCGTGATACAA } \\
\text { CGAATAGTGTCA } \\
\text { CA }\end{array}$ & $\begin{array}{l}\text { ATAATGAAACGT } \\
\text { CACGCATGACAA } \\
\text { CGAATAGTGTCA } \\
\text { CA }\end{array}$ \\
\hline Linker DNA & $\begin{array}{l}\text { GCGTCCCTCCTCG } \\
\text { TATAGTCGTAGA } \\
\text { GAGUTCTTTGTGT } \\
\text { CTTCATACAATTG } \\
\text { CACT }\end{array}$ & $\begin{array}{l}\text { GCCTTACTGCAA } \\
\text { CCCTGTTAATTCC } \\
\text { GAGUGCACCTAT } \\
\text { TCTCTCCCTGGTA } \\
\text { GCTCG }\end{array}$ & $\begin{array}{l}\text { ACATACATCGGC } \\
\text { CATTCGCAAACC } \\
\text { ATAGUGAGAACA } \\
\text { CGTGTAGCCTACT } \\
\text { TTCCTCT }\end{array}$ & $\begin{array}{l}\text { GAGTAACACCAA } \\
\text { TAATTGCTGGAC } \\
\text { AGAGUGTATAGG } \\
\text { ATTTACTACATGC } \\
\text { CCTACA }\end{array}$ & $\begin{array}{l}\text { CGTCGCACTCACT } \\
\text { CGTTGTGACACT } \\
\text { AAGCGATCTTGTT } \\
\text { GACTGTAAGCCA } \\
\text { CC }\end{array}$ & $\begin{array}{l}\text { CGTCGCACTCACT } \\
\text { CGTTGTGACACT } \\
\text { AAGCGATCTTGTT } \\
\text { GACTGTAAGCCA } \\
\text { CC }\end{array}$ \\
\hline
\end{tabular}




\begin{tabular}{|c|c|c|c|c|c|c|}
\hline GNPs probe 1 & $\begin{array}{l}\text { SS-- } \\
\text { AAAAAAAAAATA } \\
\text { CGAGGAGGGACG } \\
\text { C }\end{array}$ & $\begin{array}{l}\text { SS-- } \\
\text { AAAAAAAAAAGG } \\
\text { GTTGCAGTAAGG } \\
\text { C }\end{array}$ & $\begin{array}{l}\text { SS-- } \\
\text { AAAAAAAAAAAT } \\
\text { GGCCGATGTATG } \\
\mathrm{T}\end{array}$ & $\begin{array}{l}\text { SS-- } \\
\text { AAAAAAAAAATT } \\
\text { ATTGGTGTTACTC }\end{array}$ & $\begin{array}{l}\text { SS-- } \\
\text { AAAAAAAAAACG } \\
\text { AGTGAGTGCGAC } \\
\text { G }\end{array}$ & $\begin{array}{l}\text { SS-- } \\
\text { AAAAAAAAAACG } \\
\text { AGTGAGTGCGAC } \\
\text { G }\end{array}$ \\
\hline GNPs probe 2 & $\begin{array}{l}\text { AGTGCAATTGTA } \\
\text { TGAAAAAAAAAA } \\
\text { A--SS }\end{array}$ & $\begin{array}{l}\text { CGAGCTACCAGG } \\
\text { GAGAAAAAAAAA } \\
\text { A--SS }\end{array}$ & $\begin{array}{l}\text { AGAGGAAAGTAG } \\
\text { GCTAAAAAAAAA } \\
\text { A--SS }\end{array}$ & $\begin{array}{l}\text { TGTAGGGCATGT } \\
\text { AGTAAAAAAAAA } \\
\text { A--SS }\end{array}$ & $\begin{array}{l}\text { GGTGGCTTACAG } \\
\text { TCAAAAAAAAAA } \\
\text { A--SS }\end{array}$ & $\begin{array}{l}\text { GGTGGCTTACAG } \\
\text { TCAAAAAAAAAA } \\
\text { A--SS }\end{array}$ \\
\hline BS \#1 & $\begin{array}{l}\text { TCGATATTACCAT } \\
\text { TTACCACTTCATA } \\
\text { TCTT }\end{array}$ & $\begin{array}{l}\text { CGCAGCAATTTCT } \\
\text { ATTGCGGATTTTA } \\
\text { CCGACACATCAT } \\
\text { G }\end{array}$ & $\begin{array}{l}\text { TATCCGTCCTCGT } \\
\text { TGTACCTTTGTCC } \\
\text { ACGCTTCCTAATT } \\
\text { CTGTAATCGCTCC } \\
\text { AC }\end{array}$ & $\begin{array}{l}\text { ATATCTATATTCC } \\
\text { ATTAAATAACAA } \\
\text { TCTTC }\end{array}$ & $\begin{array}{l}\text { TTTTGCATAATTT } \\
\text { ATG } \\
\text { GTCTATTTCA }\end{array}$ & $\begin{array}{l}\text { TAGTATGCCATTT } \\
\text { GCACTTTAGGAG } \\
\text { AACAATCAATTC } \\
\text { CCTC }\end{array}$ \\
\hline BS \#2 & $\begin{array}{l}\text { CTTACTGCCTAAT } \\
\text { TCGAGTGCTACT } \\
\text { CTAG }\end{array}$ & $\begin{array}{l}\text { TCCGTACATGGCT } \\
\text { TCTTGCATAGCTT } \\
\text { CCATACGCCGTTT } \\
\text { TTTGTA }\end{array}$ & $\begin{array}{l}\text { CTGGCGTGTCTAT } \\
\text { GATGTTCACCTTC } \\
\text { GTATTTTCCCACT } \\
\text { GAAAAGAGGTTA } \\
\text { TTCC }\end{array}$ & $\begin{array}{l}\text { TTTTTTGCCCTCG } \\
\text { TGTAATTCATGTT } \\
\text { CTGGCAAATCT }\end{array}$ & $\begin{array}{l}\text { ATGGCAGTTACG } \\
\text { AAATTACACCTCT } \\
\text { GTACT }\end{array}$ & $\begin{array}{l}\text { CTGAATGATTCTG } \\
\text { ATGAATCCGTTTC } \\
\text { ATCCATTAAATAT } \\
\text { TGCA }\end{array}$ \\
\hline BS \#3 & NA & NA & NA & $\begin{array}{l}\text { CACACTATCATA } \\
\text { ACCACTACCGAT } \\
\text { TATTTC }\end{array}$ & $\begin{array}{l}\text { ACAATTTTGCGTA } \\
\text { TTATATCCGTACT } \\
\text { TATGTTATAAGGT } \\
\text { ATATTACCATAT }\end{array}$ & NA \\
\hline BS \#4 & NA & NA & NA & $\begin{array}{l}\text { AATACTATCTACT } \\
\text { TTGAAATTATCA } \\
\text { AAGTAATGCTCA }\end{array}$ & $\begin{array}{l}\text { ATTTTATAGGATT } \\
\text { GGTTTTTAGGAA } \\
\text { ATTTAAACTGCA } \\
\text { ATATATCCTTGTT } \\
\text { TAA }\end{array}$ & NA \\
\hline
\end{tabular}


Table S3. List of DNA sequences for detecting carbapenem-resistance.

\begin{tabular}{|c|c|c|c|c|}
\hline & $\boldsymbol{K P C}\left(5^{\prime}\right.$ to 3') & $\operatorname{NDM}\left(5^{\prime}\right.$ to 3') & $O X A-48$ (5' to 3') & $\boldsymbol{V I M}\left(5^{\prime}\right.$ to 3') \\
\hline Forward primer & $\begin{array}{l}\text { CAAGGGCTTTCTT } \\
\text { GCTGCCGCTGTGC } \\
\text { TGG }\end{array}$ & $\begin{array}{l}\text { AATGTCTGGCAG } \\
\text { CACACTTCCTATC } \\
\text { TCG }\end{array}$ & $\begin{array}{l}\text { TTTTTGCGATGAA } \\
\text { TATGGATATGCCC } \\
\text { ACAT }\end{array}$ & $\begin{array}{l}\text { GATGGTGATGAG } \\
\text { TTGCTTTTGATTG } \\
\text { ATAC }\end{array}$ \\
\hline Reverse primer & $\begin{array}{l}\text { CTGTTGTCAGATA } \\
\text { TTTTTCCGAGATG } \\
\text { GGTG }\end{array}$ & $\begin{array}{l}\text { CAGGTTGATCTCC } \\
\text { TGCTTGATCCAGT } \\
\text { TGA }\end{array}$ & $\begin{array}{l}\text { CTGTTTGAGCACT } \\
\text { TCTTTTGTGATGG }\end{array}$ & $\begin{array}{l}\text { GGAAGTCCAATT } \\
\text { TGCTTYTCAATCT } \\
\text { CCG }\end{array}$ \\
\hline Target & $\begin{array}{c}\text { CAAGGGCTTTCTT } \\
\text { GCTGCCGCTGTGC } \\
\text { TGGCTCGCAGCC } \\
\text { AGCAGCAGGCCG } \\
\text { GCTTGCTGGACA } \\
\text { CACCCATCCGTTA } \\
\text { CGGCAAAAATGC } \\
\text { GCTGGTTCSGTGG } \\
\text { TCACCCATCTCGG } \\
\text { AAAAATATCTGA } \\
\text { CAACAG }\end{array}$ & $\begin{array}{l}\text { AATGTCTGGCAG } \\
\text { CACACTTCCTATC } \\
\text { TCGACATGCCGG } \\
\text { GTTTCGGGGCAG } \\
\text { TCGCTTCCAACGG } \\
\text { TTTGATCGTCAGG } \\
\text { GATGGCGGCCGC } \\
\text { GTGCTGKTGGTC } \\
\text { GATACCGCCTGG } \\
\text { ACCRATGACCAG } \\
\text { ACCGCCCAGATC } \\
\text { CTCAACTGGATC } \\
\text { AAGCAGGAGATC } \\
\text { AACCTG } \\
\end{array}$ & $\begin{array}{l}\text { TTTTTGCGATGAA } \\
\text { TATGGATATGCCC } \\
\text { ACATCGGATGGT } \\
\text { TTAGGGCTGCGC } \\
\text { CAAGCCATCACA } \\
\text { AAAGAAGTGCTC } \\
\text { AAACAG }\end{array}$ & $\begin{array}{l}\text { GATGGTGATGAG } \\
\text { TTGCTTTTGATTG } \\
\text { ATACAGCGTGGG } \\
\text { GTGCGAAAAACA } \\
\text { CAGCGGCMCTTC } \\
\text { TCGCGGAGATTG } \\
\text { ARAAGCAAATTG } \\
\text { GACTTCC }\end{array}$ \\
\hline $\begin{array}{l}\text { MNAzyme left } \\
\text { arm }\end{array}$ & $\begin{array}{l}\text { CAAGATCGCTAG } \\
\text { GCTAGCTCCGGC } \\
\text { CTGCTGCTGGCTG } \\
\text { CGA }\end{array}$ & $\begin{array}{l}\text { CAAGATCGCTAG } \\
\text { GCTAGCTTCGGTC } \\
\text { CAGGCGGTATCG } \\
\text { ACC }\end{array}$ & $\begin{array}{l}\text { CAAGATCGCTAG } \\
\text { GCTAGCTAAACC } \\
\text { ATCCGATGTGGG } \\
\text { CATA }\end{array}$ & $\begin{array}{l}\text { CAAGATCGCTAG } \\
\text { GCTAGCTCCACG } \\
\text { CTGTATCAATCAA } \\
\text { AAG }\end{array}$ \\
\hline $\begin{array}{l}\text { MNAzyme right } \\
\text { arm }\end{array}$ & $\begin{array}{l}\text { GGATGGGTGTGT } \\
\text { CCAGCAAGACAA } \\
\text { CGAATAGTGTCA } \\
\text { CA } \\
\end{array}$ & $\begin{array}{l}\text { GGATCTGGGCGG } \\
\text { TCTGGTCAACAA } \\
\text { CGAATAGTGTCA } \\
\text { CA }\end{array}$ & $\begin{array}{l}\text { TGATGGCTTGGC } \\
\text { GCAGCCCTACAA } \\
\text { CGAATAGTGTCA } \\
\text { CA }\end{array}$ & $\begin{array}{l}\text { GCCGCTGTGTTTT } \\
\text { TCGCACCACAAC } \\
\text { GAATAGTGTCAC } \\
\text { A }\end{array}$ \\
\hline Linker DNA & $\begin{array}{l}\text { CGTCGCACTCACT } \\
\text { CGTTGTGACACTA } \\
\text { AGCGATCTTGTTG } \\
\text { ACTGTAAGCCAC } \\
\text { C }\end{array}$ & $\begin{array}{l}\text { CGTCGCACTCACT } \\
\text { CGTTGTGACACTA } \\
\text { AGCGATCTTGTTG } \\
\text { ACTGTAAGCCAC } \\
\text { C }\end{array}$ & $\begin{array}{l}\text { CGTCGCACTCACT } \\
\text { CGTTGTGACACTA } \\
\text { AGCGATCTTGTTG } \\
\text { ACTGTAAGCCAC } \\
\text { C }\end{array}$ & $\begin{array}{l}\text { CGTCGCACTCACT } \\
\text { CGTTGTGACACTA } \\
\text { AGCGATCTTGTTG } \\
\text { ACTGTAAGCCAC } \\
\text { C }\end{array}$ \\
\hline GNPs probe 1 & $\begin{array}{l}\text { SS-- } \\
\text { AAAAAAAAAACG } \\
\text { AGTGAGTGCGAC } \\
\text { G } \\
\end{array}$ & $\begin{array}{l}\text { SS-- } \\
\text { AAAAAAAAAACG } \\
\text { AGTGAGTGCGAC } \\
\text { G } \\
\end{array}$ & $\begin{array}{l}\text { SS-- } \\
\text { AAAAAAAAAACG } \\
\text { AGTGAGTGCGAC } \\
\text { G } \\
\end{array}$ & $\begin{array}{l}\text { SS-- } \\
\text { AAAAAAAAAACG } \\
\text { AGTGAGTGCGAC } \\
\text { G }\end{array}$ \\
\hline
\end{tabular}




\begin{tabular}{|c|c|c|c|c|}
\hline GNPs probe 2 & $\begin{array}{l}\text { GGTGGCTTACAG } \\
\text { TCAAAAAAAAAA } \\
\text { A--SS }\end{array}$ & $\begin{array}{l}\text { GGTGGCTTACAG } \\
\text { TCAAAAAAAAAA } \\
\text { A--SS }\end{array}$ & $\begin{array}{l}\text { GGTGGCTTACAG } \\
\text { TCAAAAAAAAAA } \\
\text { A--SS }\end{array}$ & $\begin{array}{l}\text { GGTGGCTTACAG } \\
\text { TCAAAAAAAAAA } \\
\text { A--SS }\end{array}$ \\
\hline BS \#1 & $\begin{array}{l}\text { GCCAGCACAG } \\
\text { CGGCAGCAAG } \\
\text { AAAGCCCTTG }\end{array}$ & $\begin{array}{l}\text { ACTGCCCCGA } \\
\text { AACTCGGCAT } \\
\text { GTCGAGATAG } \\
\text { GAAGTGTGCT } \\
\text { GCCAGACATT }\end{array}$ & $\begin{array}{l}\text { TCCATATTCATCG } \\
\text { CAAAAA }\end{array}$ & $\begin{array}{l}\text { CAACTCATCACC } \\
\text { ATC }\end{array}$ \\
\hline$\overline{B S}$ \#2 & $\begin{array}{l}\text { TGTTGTCAGA } \\
\text { TATTTTTCCG } \\
\text { AGATGGGTGA } \\
\text { CCACCGAACC } \\
\text { AGCGCATTTT } \\
\text { TGCCGTAAC } \\
\end{array}$ & $\begin{array}{l}\text { ACCAGCACGCGG } \\
\text { CCGCCATCCCTGA } \\
\text { CGATCAAACCGT } \\
\text { TGGAAGTG }\end{array}$ & $\begin{array}{l}\text { CTGTTTGAGCACT } \\
\text { TCTTTTG }\end{array}$ & $\begin{array}{l}\text { GGAAGTCCAATT } \\
\text { TGCTTTTCAATCT } \\
\text { CCGCGAG AAGT }\end{array}$ \\
\hline$\overline{B S} \# \mathbf{3}$ & $\mathrm{N} / \mathrm{A}$ & $\begin{array}{l}\text { CAGGTTGATCTCC } \\
\text { TGCTTGATCCAGT } \\
\text { TGA }\end{array}$ & N/A & N/A \\
\hline
\end{tabular}


Table S4. List of DNA sequences for the CLABSI-associated bacteria.

\begin{tabular}{|c|c|c|c|c|c|c|c|}
\hline & E. coli (5' to 3') & $\begin{array}{l}\text { E. faecalis (5' to } \\
\text { 3') }\end{array}$ & $\begin{array}{l}\text { E. faecium (5' to } \\
\text { 3') }\end{array}$ & $\begin{array}{l}\text { Klebsiella spp. } \\
\text { (5' to 3') }\end{array}$ & $\begin{array}{l}\text { P. aeruginosa (5' } \\
\left.\text { to } 3^{\prime}\right)\end{array}$ & $\begin{array}{l}\text { S. aureus (5' to } \\
\text { 3') }\end{array}$ & $\begin{array}{l}\text { S. epidermis (5' } \\
\text { to 3') }\end{array}$ \\
\hline Forward primer & $\begin{array}{l}\text { ATATGGCGGTG } \\
\text { AGTATTATCGT } \\
\text { CAGGAACAACA } \\
\text { TC }\end{array}$ & $\begin{array}{l}\text { TCAGGAAAAC } \\
\text { GAATCAGTCC } \\
\mathrm{T}\end{array}$ & $\begin{array}{l}\text { TATATTTTACA } \\
\text { AGCTGCTGGT } \\
\text { GTG }\end{array}$ & $\begin{array}{l}\text { CATGCAAGTC } \\
\text { GAGCGGTAGC } \\
\text { AC }\end{array}$ & $\begin{array}{l}\text { CTAATACCGC } \\
\text { ATACGTCCTG } \\
\text { AGGGAGAAAG }\end{array}$ & $\begin{array}{l}\text { AGTATTAATC } \\
\text { ACAATATCGT } \\
\text { AGAG }\end{array}$ & $\begin{array}{l}\text { ATCAAAAAGT } \\
\text { TGGCGAACCT } \\
\text { TTTCA }\end{array}$ \\
\hline Reverse primer & $\begin{array}{l}\text { GAGATGACCAT } \\
\text { TTGTCGGCATC } \\
\text { AACATCTTTGT } \\
\text { AG }\end{array}$ & $\begin{array}{l}\text { ATCCTTGAATT } \\
\text { GTTCCATCTTC }\end{array}$ & $\begin{array}{l}\text { CTTCACATTG } \\
\text { ATCAAATACT }\end{array}$ & $\begin{array}{l}\text { TAGTTATCCCC } \\
\text { CTCCATC }\end{array}$ & $\begin{array}{l}\text { CTAATCCGAC } \\
\text { CTAGGCTCAT } \\
\text { CTGATAG }\end{array}$ & $\begin{array}{l}\text { CATGTTTGAA } \\
\text { TTTAATATATT } \\
\text { TAGGTGTTG }\end{array}$ & $\begin{array}{l}\text { CAAAAGAGCG } \\
\text { TGGAGAAAAG } \\
\text { TATCA }\end{array}$ \\
\hline Target & $\begin{array}{l}\text { GAGATGACCAT } \\
\text { TTGTCGGCATC } \\
\text { AACATCTTTGT } \\
\text { AGCCGTCGCTG } \\
\text { CTACCGCGATA } \\
\text { ACTGTCATAGC } \\
\text { GGGTTCCGCCA } \\
\text { AGCAGGGTAAT } \\
\text { CGGCAGATCGC } \\
\text { GTAAGGTGATC } \\
\text { TCATCTTGTAGC } \\
\text { CAGCCAGAGCT } \\
\text { AAAATCGATTT } \\
\text { TTGCTTGCGGG } \\
\text { AAGCCCGTCGT } \\
\text { CGCGCCACCCG } \\
\text { GATGTTGTTCCT } \\
\text { GACGATAATAC } \\
\text { TCACCGCCATA } \\
\text { T }\end{array}$ & $\begin{array}{l}\text { TCAGGAAAAC } \\
\text { GAATCAGTCC } \\
\text { TTCGGAAATT } \\
\text { TATGAAGAAG } \\
\text { AAGCGATTGT } \\
\text { TTTCCCTGTTT } \\
\text { TACATGGGCC } \\
\text { AAATGGTGAA } \\
\text { GATGGAACAA } \\
\text { TTCAAGGAT }\end{array}$ & $\begin{array}{l}\text { TATATTTTACA } \\
\text { AGCTGCTGGT } \\
\text { GTGCCGCAAG } \\
\text { TTCCTTATGTA } \\
\text { CCAGTACTTA } \\
\text { AGAATCAATG } \\
\text { GAAAGAAAAT } \\
\text { CCTAAAAAAG } \\
\text { TATTTGATCA } \\
\text { ATGTGAAG }\end{array}$ & $\begin{array}{l}\text { CATGCAAGTC } \\
\text { GAGCGGTAGC } \\
\text { ACAGAGAGCT } \\
\text { TGCTCTCGGG } \\
\text { TGACGAGCGG } \\
\text { CGGACGGGTG } \\
\text { AGTAATGTCT } \\
\text { GGGAAACTGC } \\
\text { CTGATGGAGG } \\
\text { GGGATAACTA }\end{array}$ & $\begin{array}{l}\text { CTAATACCGC } \\
\text { ATACGTCCTG } \\
\text { AGGGAGAAAG } \\
\text { TGGGGGATCT } \\
\text { TCGGACCTCA } \\
\text { CGCTATCAGA } \\
\text { TGAGCCTAGG } \\
\text { TCGGATTAG }\end{array}$ & $\begin{array}{l}\text { AGTATTAATC } \\
\text { ACAATATCGT } \\
\text { AGAGTACAAT } \\
\text { GATGGTACTT } \\
\text { TTAAATATCA } \\
\text { ATCTAGACCA } \\
\text { AAATTTAACT } \\
\text { CAACACCTAA } \\
\text { ATATATTAAA } \\
\text { TTCAAACATG }\end{array}$ & $\begin{array}{l}\text { CAAAAGAGCG } \\
\text { TGGAGAAAAG } \\
\text { TATCAAGACT } \\
\text { TTGAGCAATC } \\
\text { AGACTATGCA } \\
\text { AATGGTAAAT } \\
\text { ATTTTGAATTC } \\
\text { TATACATCTC } \\
\text { AAGAATTTGA } \\
\text { ACCAAAATTT } \\
\text { GAAAAGGTTC } \\
\text { GCCAACTTTTT } \\
\text { GAT }\end{array}$ \\
\hline $\begin{array}{l}\text { MNAzyme left } \\
\text { arm }\end{array}$ & $\begin{array}{l}\text { CAAGATCGCTA } \\
\text { GGCTAGCTACA } \\
\text { GTTATCGCGGT } \\
\text { AGCAGCG }\end{array}$ & $\begin{array}{l}\text { CAAGATCGCT } \\
\text { AGGCTAGCTA } \\
\text { CAATCGCTTCT } \\
\text { TCTTCATAA }\end{array}$ & $\begin{array}{l}\text { CAAGATCGCT } \\
\text { AGGCTAGCTA } \\
\text { GTACTGGTAC } \\
\text { ATAAGGAACT }\end{array}$ & $\begin{array}{l}\text { CAAGATCGCT } \\
\text { AGGCTAGCTT } \\
\text { GCTACCGCTC } \\
\text { GACTTGCATG }\end{array}$ & $\begin{array}{l}\text { CAAGATCGCT } \\
\text { AGGCTAGCTG } \\
\text { ATCCCCCACTT } \\
\text { TCTCCCTCA }\end{array}$ & $\begin{array}{l}\text { CAAGATCGCT } \\
\text { AGGCTAGCTT } \\
\text { GATATTTAAA } \\
\text { AGTACCATCA }\end{array}$ & $\begin{array}{l}\text { CAAGATCGCT } \\
\text { AGGCTAGCTT } \\
\text { ATTTACCATTT } \\
\text { GCATAGTCT }\end{array}$ \\
\hline $\begin{array}{l}\text { MNAzyme right } \\
\text { arm }\end{array}$ & $\begin{array}{l}\text { GCTTGGCGGAA } \\
\text { CCCGCTATGAC } \\
\text { AACGAATAGTG } \\
\text { TCACA }\end{array}$ & $\begin{array}{l}\text { GCCCATGTAA } \\
\text { AACAGGGAAA } \\
\text { ACAACGAATA } \\
\text { GTGTCACA } \\
\end{array}$ & $\begin{array}{l}\text { TTTCTTTCCAT } \\
\text { TGATTCTTAAC } \\
\text { AACGAATAGT } \\
\text { GTCACA } \\
\end{array}$ & $\begin{array}{l}\text { ACCCGAGAGC } \\
\text { AAGCTCTCTG } \\
\text { ACAACGAATA } \\
\text { GTGTCACA } \\
\end{array}$ & $\begin{array}{l}\text { CTGATAGCGT } \\
\text { GAGGTCCGAA } \\
\text { ACAACGAATA } \\
\text { GTGTCACA } \\
\end{array}$ & $\begin{array}{l}\text { AGTTAAATTTT } \\
\text { GGTCTAGATA } \\
\text { CAACGAATAG } \\
\text { TGTCACA } \\
\end{array}$ & $\begin{array}{l}\text { GAGATGTATA } \\
\text { GAATTCAAAA } \\
\text { ACAACGAATA } \\
\text { GTGTCACA } \\
\end{array}$ \\
\hline
\end{tabular}




\begin{tabular}{|c|c|c|c|c|c|c|c|}
\hline Linker DNA & $\begin{array}{l}\text { CGTCGCACTCA } \\
\text { CTCGTTGTGAC } \\
\text { ACTAAGCGATC } \\
\text { TTGTTGACTGTA } \\
\text { AGCCACC }\end{array}$ & $\begin{array}{l}\text { CGTCGCACTC } \\
\text { ACTCGTTGTG } \\
\text { ACACTAAGCG } \\
\text { ATCTTGTTGAC } \\
\text { TGTAAGCCAC } \\
\text { C }\end{array}$ & $\begin{array}{l}\text { CGTCGCACTC } \\
\text { ACTCGTTGTG } \\
\text { ACACTAAGCG } \\
\text { ATCTTGTTGAC } \\
\text { TGTAAGCCAC } \\
\text { C }\end{array}$ & $\begin{array}{l}\text { CGTCGCACTC } \\
\text { ACTCGTTGTG } \\
\text { ACACTAAGCG } \\
\text { ATCTTGTTGAC } \\
\text { TGTAAGCCAC } \\
\text { C }\end{array}$ & $\begin{array}{l}\text { CGTCGCACTC } \\
\text { ACTCGTTGTG } \\
\text { ACACTAAGCG } \\
\text { ATCTTGTTGAC } \\
\text { TGTAAGCCAC } \\
\text { C }\end{array}$ & $\begin{array}{l}\text { CGTCGCACTC } \\
\text { ACTCGTTGTG } \\
\text { ACACTAAGCG } \\
\text { ATCTTGTTGAC } \\
\text { TGTAAGCCAC } \\
\text { C }\end{array}$ & $\begin{array}{l}\text { CGTCGCACTC } \\
\text { ACTCGTTGTG } \\
\text { ACACTAAGCG } \\
\text { ATCTTGTTGAC } \\
\text { TGTAAGCCAC } \\
\text { C }\end{array}$ \\
\hline GNPs probe 1 & $\begin{array}{l}\text { SS-- } \\
\text { AAAAAAAAAAC } \\
\text { GAGTGAGTGCG } \\
\text { ACG }\end{array}$ & $\begin{array}{l}\text { SS-- } \\
\text { AAAAAAAAAA } \\
\text { CGAGTGAGTG } \\
\text { CGACG }\end{array}$ & $\begin{array}{l}\text { SS-- } \\
\text { AAAAAAAAAA } \\
\text { CGAGTGAGTG } \\
\text { CGACG }\end{array}$ & $\begin{array}{l}\text { SS-- } \\
\text { AAAAAAAAAA } \\
\text { CGAGTGAGTG } \\
\text { CGACG }\end{array}$ & $\begin{array}{l}\text { SS-- } \\
\text { AAAAAAAAAA } \\
\text { CGAGTGAGTG } \\
\text { CGACG }\end{array}$ & $\begin{array}{l}\text { SS-- } \\
\text { AAAAAAAAAA } \\
\text { CGAGTGAGTG } \\
\text { CGACG }\end{array}$ & $\begin{array}{l}\text { SS-- } \\
\text { AAAAAAAAAA } \\
\text { CGAGTGAGTG } \\
\text { CGACG }\end{array}$ \\
\hline GNPs probe 2 & $\begin{array}{l}\text { GGTGGCTTACA } \\
\text { GTCAAAAAAAA } \\
\text { AAA--SS }\end{array}$ & $\begin{array}{l}\text { GGTGGCTTAC } \\
\text { AGTCAAAAAA } \\
\text { AAAAA--SS } \\
\end{array}$ & $\begin{array}{l}\text { GGTGGCTTAC } \\
\text { AGTCAAAAAA } \\
\text { AAAAA--SS } \\
\end{array}$ & $\begin{array}{l}\text { GGTGGCTTAC } \\
\text { AGTCAAAAAA } \\
\text { AAAAA--SS } \\
\end{array}$ & $\begin{array}{l}\text { GGTGGCTTAC } \\
\text { AGTCAAAAAA } \\
\text { AAAAA--SS } \\
\end{array}$ & $\begin{array}{l}\text { GGTGGCTTAC } \\
\text { AGTCAAAAAA } \\
\text { AAAAA--SS } \\
\end{array}$ & $\begin{array}{l}\text { GGTGGCTTAC } \\
\text { AGTCAAAAAA } \\
\text { AAAAA--SS } \\
\end{array}$ \\
\hline BS \#1 & $\begin{array}{l}\text { ACGGCTACAAA } \\
\text { GATGTTGATGC } \\
\text { CGACAAATGGT } \\
\text { CATCTCG }\end{array}$ & $\begin{array}{l}\text { ATTTCCGAAG } \\
\text { GACTGATTCG } \\
\text { TTTTCCTGA }\end{array}$ & $\begin{array}{l}\text { TGCGGCACAC } \\
\text { CAGCAGCTTG } \\
\text { TAAAATATA }\end{array}$ & $\begin{array}{l}\text { TAGTTATCCCC } \\
\text { CTCCATCAGG } \\
\text { CAGTTTCC }\end{array}$ & $\begin{array}{l}\text { GGACGTATGC } \\
\text { GGTATTAG }\end{array}$ & $\begin{array}{l}\text { TTGTACTCTAC } \\
\text { GATATTGTGA } \\
\text { TTAATACT }\end{array}$ & $\begin{array}{l}\text { GATTGCTCAA } \\
\text { AGTCTTGATA } \\
\text { CTTTTCTCCAC } \\
\text { GCTCTTTTG }\end{array}$ \\
\hline BS \#2 & $\begin{array}{l}\text { ACATATGGCGG } \\
\text { TGAGTATTATC } \\
\text { GTCAGGAACAA } \\
\text { CATCCGGGTGG } \\
\text { CGCGA }\end{array}$ & $\begin{array}{l}\text { ATCCTTGAATT } \\
\text { GTTCCATCTTC } \\
\text { ACCATTTG }\end{array}$ & $\begin{array}{l}\text { CTTCACATTG } \\
\text { ATCAAATACT } \\
\text { TTTTTAGGAT }\end{array}$ & $\begin{array}{l}\text { CAGACATTAC } \\
\text { TCACCCGTCC } \\
\text { GCCGCTCGT C }\end{array}$ & $\begin{array}{l}\text { CTAATCCGAC } \\
\text { CTAGGCTCAT }\end{array}$ & $\begin{array}{l}\text { CATGTTTGAA } \\
\text { TTTAATATATT } \\
\text { TAGGTGTTG }\end{array}$ & $\begin{array}{l}\text { ATCAAAAAGT } \\
\text { TGGCGAACCT } \\
\text { TTTCAAATTTT } \\
\text { GGTTCAAATT } \\
\text { CTT }\end{array}$ \\
\hline BS \#3 & $\begin{array}{l}\text { CGACGGGCTTC } \\
\text { CCGCAAGCAAA } \\
\text { AATCGATTTTA } \\
\text { GCTCTGGCT }\end{array}$ & N/A & N/A & N/A & N/A & $\mathrm{N} / \mathrm{A}$ & $\mathrm{N} / \mathrm{A}$ \\
\hline BS \#4 & $\begin{array}{l}\text { GGCTACAAGAT } \\
\text { GAGATCACCTT } \\
\text { ACGCGATCTGC } \\
\text { CGATTACCCT } \\
\end{array}$ & N/A & N/A & N/A & N/A & N/A & $\mathrm{N} / \mathrm{A}$ \\
\hline
\end{tabular}


Table S5. Antibiotic resistance genes panel and their prevalence in S. aureus.

\begin{tabular}{|c|c|c|c|c|}
\hline \multirow{2}{*}{ Antibiotic class } & Antibiotic & $\begin{array}{c}\text { Antibiotic } \\
\text { resistance genes }\end{array}$ & Prevalence (\%) & References \\
\hline B-lactam & Oxacillin & mecA & 96.0 & $2-8$ \\
\cline { 2 - 5 } & Penicillin & blaZ & 99.5 & $8-12$ \\
\hline Glycopeptides & Vancomycin & vanA \& vanB & 97.8 & $13-15$ \\
\hline Tetracyclines & Tetracycline & tetK \& tet $M$ & 93.2 & $7,8,16-20$ \\
\hline Aminoglycosides & Gentamicin & acc6 \& aph3iiia & 83.0 & $8,16,21$ \\
\hline Macrolides & Erythromycin & ermA \& ermC & 91.2 & $7,8,19,22-25$ \\
\hline
\end{tabular}


Table S6. Clinical sensitivity and specificity of panel for carbapenem resistance in clinical isolates.

\begin{tabular}{|l|l|l|l|}
\hline AMR gene & Bacteria & Sensitivity (\%) & Specificity (\%) \\
\hline KPC & Enterobacter spp. & $3 / 3(100 \%)$ & $9 / 9(100 \%)$ \\
\hline NDM & Escherichia coli & $3 / 3(100 \%)$ & $9 / 9(100 \%)$ \\
\hline \multirow{2}{*}{ OXA-48 } & Escherichia coli & $2 / 2(100 \%)$ & $9 / 9(100 \%)$ \\
\cline { 2 - 3 } & Klebsiella pneumoniae & $1 / 1(100 \%)$ & \\
\hline VIM & Enterobacter spp. & $2 / 2(100 \%)$ & $9 / 9(100 \%)$ \\
\hline
\end{tabular}


Table S7. Positive test results of CLABSI panel in clinical isolates.

\begin{tabular}{|c|c|c|c|c|c|c|}
\hline \multirow[b]{2}{*}{ Culture result } & \multicolumn{6}{|c|}{ MNAzyme-GNP target } \\
\hline & E. faecalis & E. faecium & Klebsiella spp. & $P$. aeruginosa & S. aureus & $\begin{array}{l}S . \\
\text { epidermis }\end{array}$ \\
\hline Candida spp. & $0 \%(0 / 3)$ & $0 \%(0 / 3)$ & $0 \%(0 / 3)$ & $0 \%(0 / 3)$ & $0 \%(0 / 3)$ & $0 \%(0 / 3)$ \\
\hline E. coli & $0 \%(0 / 4)$ & $0 \%(0 / 4)$ & $0 \%(0 / 4)$ & $0 \%(0 / 4)$ & $0 \%(0 / 4)$ & $0 \%(0 / 4)$ \\
\hline E. faecalis & $100 \%(3 / 3)$ & $0 \%(0 / 3)$ & $0 \%(0 / 3)$ & $0 \%(0 / 3)$ & $0 \%(0 / 3)$ & $0 \%(0 / 3)$ \\
\hline E. faecium & $0 \%(0 / 3)$ & $100 \%(3 / 3)$ & $0 \%(0 / 3)$ & $0 \%(0 / 3)$ & $0 \%(0 / 3)$ & $0 \%(0 / 3)$ \\
\hline $\begin{array}{l}\text { Enterobacter } \\
\text { cloacae }\end{array}$ & $0 \%(0 / 3)$ & $0 \%(0 / 3)$ & $0 \%(0 / 3)$ & $0 \%(0 / 3)$ & $33.3 \%(1 / 3)$ & $0 \%(0 / 3)$ \\
\hline Klebsiella spp. & $0 \%(0 / 6)$ & $0 \%(0 / 6)$ & $100 \%(6 / 6)$ & $0 \%(0 / 6)$ & $0 \%(0 / 6)$ & $0 \%(0 / 6)$ \\
\hline P. aeruginosa & $0 \%(0 / 3)$ & $0 \%(0 / 3)$ & $0 \%(0 / 3)$ & $100 \%(3 / 3)$ & $0 \%(0 / 3)$ & $0 \%(0 / 3)$ \\
\hline S. aureus & $0 \%(0 / 3)$ & $0 \%(0 / 3)$ & $0 \%(0 / 3)$ & $0 \%(0 / 3)$ & $100 \%(3 / 3)$ & $0 \%(0 / 3)$ \\
\hline S. epidermis & $0 \%(0 / 4)$ & $0 \%(0 / 4)$ & $0 \%(0 / 4)$ & $0 \%(0 / 4)$ & $0 \%(0 / 4)$ & $\begin{array}{l}100 \% \\
(4 / 4)\end{array}$ \\
\hline S. hemolyticus & $2 / 5$ & & & & & \\
\hline Clinical specificity & $94.3 \%(2 /$ & $100 \%$ & $100 \%$ & $100 \%$ & $97.1 \%$ & $100 \%$ \\
\hline
\end{tabular}




\section{SI References}

(1) Kelly, A. M.; Mathema, B.; Larson, E. L. Carbapenem-Resistant Enterobacteriaceae in the Community: A Scoping Review. International Journal of Antimicrobial Agents, 2017, 50, 127-134. Asghar, A. Molecular Characterization of Methicillin-Resistant Staphylococcus aureus Isolated from Tertiary Care Hospitals. Pakistan J. Med. Sci. 2014, 30, 698-702.

(3) Elhassan, M. M.; Ozbak, H. A.; Hemeg, H. A.; Elmekki, M. A.; Ahmed, L. M. Absence of the Gene in Methicillin Resistant Staphylococcus aureus Isolated from Different Clinical Specimens in Shendi City, Sudan. Biomed. Res. Int. 2015, 2015, 1-5.

(4) Martineau, F.; Picard, . J.; Lansac, N.; , C.; Roy, P. H.; Ouellette, M.; Bergeron, M. . Correlation between the Resistance Genotype Determined by Multiplex PCR Assays and the Antibiotic Susceptibility Patterns of Staphylococcus aureus and Staphylococcus Epidermidis. Antimicrob. Agents Chemother. 2000, 44, 231-238.

(5) Sajith, K. A.; Shetty, P. J.; Lakshmi, S. Y.; Chidambaram, A.; Ranganathan, R. Detection of MecA Genes of Methicillin-Resistant Staphylococcus aureus by Polymerase Chain Reaction. 2012, 1, 6468.

(6) Petinaki, E.; Arvaniti, A.; Dimitracopoulos, G.; Spiliopoulou, I. Detection of MecA, MecRl and $\mathrm{MecI}$ Genes among Clinical Isolates of Methicillin-Resistant Staphylococci by Combined Polymerase Chain Reactions. J. Antimicrob. Chemother. 2001, 47, 297-304.

(7) Strommenger, B.; Kettlitz, C.; Werner, G.; Witte, W. Multiplex PCR Assay for Simultaneous Detection of Nine Clinically Relevant Antibiotic Resistance Genes in Staphylococcus aureus. J. Clin. Microbiol. 2003, 41, 4089-4094.

(8) Duran, N.; Ozer, B.; Duran, G. G.; Onlen, Y.; Demir, C. Antibiotic Resistance Genes \& Susceptibility Patterns in Staphylococci. Indian J. od Med. Res. 2012, 135, 389-396.

(9) Haveri, M.; Suominen, S.; Rantala, L.; Pyo, S. Comparison of Phenotypic and Genotypic Detection of Penicillin G Resistance of Staphylococcus aureus Isolated from Bovine Intramammary Infection. Vet. Microbiol. 2005, 106, 97-102.

(10) Pereira, L. A.; Harnett, G. B.; Hodge, M. M.; Cattell, J. A.; Speers, J. Real-Time PCR Assay for Detection of BlaZ Genes in Staphylococcus Aureus Clinical Isolates. J. Clin. Microbiol. 2014, 52, 1259-1261.

(11) Richter, S. S.; Doern, G. V; Heilmann, K. P.; Miner, S.; Tendolkar, S.; Riahi, F.; Diekema, D. J. Detection and Prevalence of Penicillin-Susceptible Staphylococcus aureus in the United States in 2013. J. Clin. Microbiol. 2016, 54, 812-814.

(12) Yang, F.; Wang, Q.; Wang, X.; Wang, L.; Xiao, M.; Li, X. Prevalence of BlaZ Gene and Other Virulence Genes in Penicillin-Resistant Staphylococcus aureus Isolated from Bovine Mastitis Cases in Gansu, China. Turkish J. Vet. Anim. Sci. 2015, 39, 634-636.

(13) Thati, V.; Shivannavar, C. T.; Gaddad, S. M. Vancomycin Resistance among Methicillin Resistant Staphylococcus aureus Isolates from Intensive Care Units of Tertiary Care Hospitals in Hyderabad. Indian J. Med. Res. 2011, 134, 704-708.

(14) Saadat, S.; Solhjoo, K.; Kazemi, A. VanA and VanB Positive Vancomycin-Resistant Staphylococcus aureus Among Clinical Isolates in Shiraz, South of Iran. Oman Med. J. 2014, 29, 335-339.

(15) Okolie, C. E.; Cockayne, A.; Wooldridge, K.; James, R. Development and Validation of a New Diagnostic PCR Assay for VanA Gene Encoding Vancomycin Resistance in Staphylococcus aureus. Int. J. Appl. Microbiol. Biotechnol. Res. 2014, 2, 1-10.

(16) Emaneini, M.; Bigverdi, R.; Kalantar, D.; Soroush, S.; Jabalameli, F.; Noorazar Khoshgnab, B.; Asadollahi, P.; Taherikalani, M. Distribution of Genes Encoding Tetracycline Resistance and Aminoglycoside Modifying Enzymes in Staphylococcus aureus Strains Isolated from a Burn Center. Ann. Burns Fire Disasters 2013, 26, 76-80.

(17) Schmitz, F.-J.; Krey, A.; Sadurski, R.; Verhoef, J.; Milatovic, D.; Fluit, A. C. Resistance to Tetracycline and Distribution of Tetracycline Resistance Genes in European Staphylococcus aureus Isolates. J Antimicrob Chemother 2001, 47, 239-240.

(18) Xu, J.; Shi, C.; Song, M.; Xu, X.; Yang, P.; Paoli, G.; Shi, X. Phenotypic and Genotypic Antimicrobial Resistance Traits of Foodborne Staphylococcus aureus Isolates from Shanghai. J. Food Sci. 2014, 79, 635-642.

(19) Sekiguchi, J.; Fujino, T.; Saruta, K.; Kawano, F.; Takami, J.; Miyazaki, H.; Kuratsuji, T.; Yoshikura, H.; Kirikae, T. Spread of Erythromycin- , Tetracycline- , and Aminoglycoside-Resistant 
Genes in Methicillin-Resistant Staphylococcus aureus Clinical Isolates in a Kumamoto Hospital. Jpn. J. Infect. Dis. 2003, 56, 133-137.

(20) Ullah, F.; Malik, S. A.; Ahmed, J.; Ullah, F.; Ayaz, M.; Hussain, S.; Khatoon, L. Investigation of the Genetic Basis of Tetracycline Resistance in Staphylococcus aureus from Pakistan. Trop. J.

Pharm. Res. 2012, 11, 925-931.

(21) Schmitz, F.; Fluit, A. C.; Gondolf, M.; Beyrau, R.; Lindenlauf, E. The Prevalence of Aminoglycoside Resistance and Corresponding Resistance Genes in Clinical Isolates of Staphylococci from 19 European Hospitals. 1999, 43, 253-259.

(22) Westh, H.; Hougaard, D. M.; Vuust, J.; Rosdahl, V. T. Prevalence of Erm Gene Classes in Erythromycin-Resistant Staphylococcus aureus Strains Isolated between 1959 and 1988. Antimicrob. Agents Chemother. 1995, 39, 369-373.

(23) Khan, S.; Nawaz, M.; Khan, A.; Cerniglia, C. Simultaneous Detection of Erythromycin-Resistant Methylase Genes ErmA and ErmC from Staphylococcus Spp . by Multiplex-PCR. Mol. Cell. Probes 1999, 13, 381-387.

(24) Schmitz, F.; Sadurski, R.; Kray, A.; Boos, M.; Geisel, R.; Köhrer, K.; Verhoef, J.; Fluit, A. C. Prevalence of Macrolide-Resistance Genes in Staphylococcus aureus and Enterococcus faecium Isolates from 24 European University Hospitals. J. Antimicrob. Chemother. 2000, 45, 891-894.

(25) Lim, J.-A.; Kwon, A.-R.; Kim, S.-K.; Chong, Y.; Lee, K.; Choi, E.-C. Prevalence of Resistance to Macrolide, Lincosamide and Streptogramin Antibiotics in Gram-Positive Cocci Isolated in a Korean Hospital. J. Antimicrob. Chemother. 2002, 49, 489-495. 